\title{
Experimental and numerical investigations of bi-injection moulding of PA66/LSR peel test specimens
}

\author{
M. Sahli ${ }^{1}$, T. Barrière ${ }^{1}$ and X. Roizard ${ }^{1}$ \\ ${ }^{1}$ Univ. Bourgogne Franche-Comté, FEMTO-ST Institute, CNRS/UFC/ENSMM/UTBM, \\ Department of Applied Mechanics, 25000 Besançon, France \\ mohamed.sahli@,femto-st.fr
}

\begin{abstract}
Bi-injection moulding is a widely used process to manufacture engineering products and consumer goods. Typically, a thermoplastic is combined with rubber or another thermoplastic to create colour differences or hard and soft areas, respectively. The aim of this study was to optimise the injection parameters and processing conditions for the moulding of twocomponent standard peel test specimens with suitable functional properties. In this work, all parameters of thermo-rheo-kinetic behaviour were identified to predict the entire filling stage and the effect of a liquid silicone rubber cross-linking reaction during the injection moulding process. The models of Carreau-Yasuda and Isayev-Deng regarding the thermal dependence assumed by Arrhenius' law were used.

In our study, over-injection moulding is simulated and examined using finite element software (Cadmould 3D) to investigate the thermo-rheo-kinetic behaviour and the adhesion of liquid silicone rubber during the filling mould process in over-moulding. Numerical simulation results were then compared with the experimental results, and good agreement was obtained.
\end{abstract}

Keywords: Bi-injection moulding process, rheokinetics, liquid silicone rubber, polymers, viscosities, finite element analysis.

\section{Introduction}

The injection moulding process is the most widely used forming technique for the manufacture of thermoplastic components due to its high productivity for manufacturing items having various geometries and complex shapes [1-3]. This process characterised by a high production rate and low manufacturing cost. Injection moulding offers a wide range of possibilities for producing multi-material, multi-coloured parts or parts that present novel functionalities to meet the ever-increasing requirements for devices used in security, automotive, home automation, biomedical, and other applications [4-5]. 
A liquid silicone rubber (LSR) injection moulding process is similar to a conventional thermoplastic injection process; the primary difference is that the LSR injection includes a vulcanisation phase [6-7]. Before materials are injected into die cavities, they are heated to a molten state and then transported using an injection screw to fill the tool [8-10]. The materials are mixed using a specific LSR dosing pump system and then cold-injected into a singlecavity or multi-cavities that are preheated to a given temperature. The LSR rubber solidifies by a chemical reaction that occurs during the exothermic vulcanisation phase [11-16]. The LSR rubber is cured by a hydrosilylation reaction catalysed by platinum; this step requires a long solidification time relative to the injection cycle time [17-18].

Rubber is usually over-moulded onto another chemically compatible substrate using insertion moulding or multi-shot injection moulding processes (see Fig.1). The quality of bicomponent materials fabricated by over-moulding processes primarily depend on the strength of interfacial adhesion [19-22]. In this context, numerical simulations play a valuable role and provides solutions for improving productivity and shortening the production cycle.

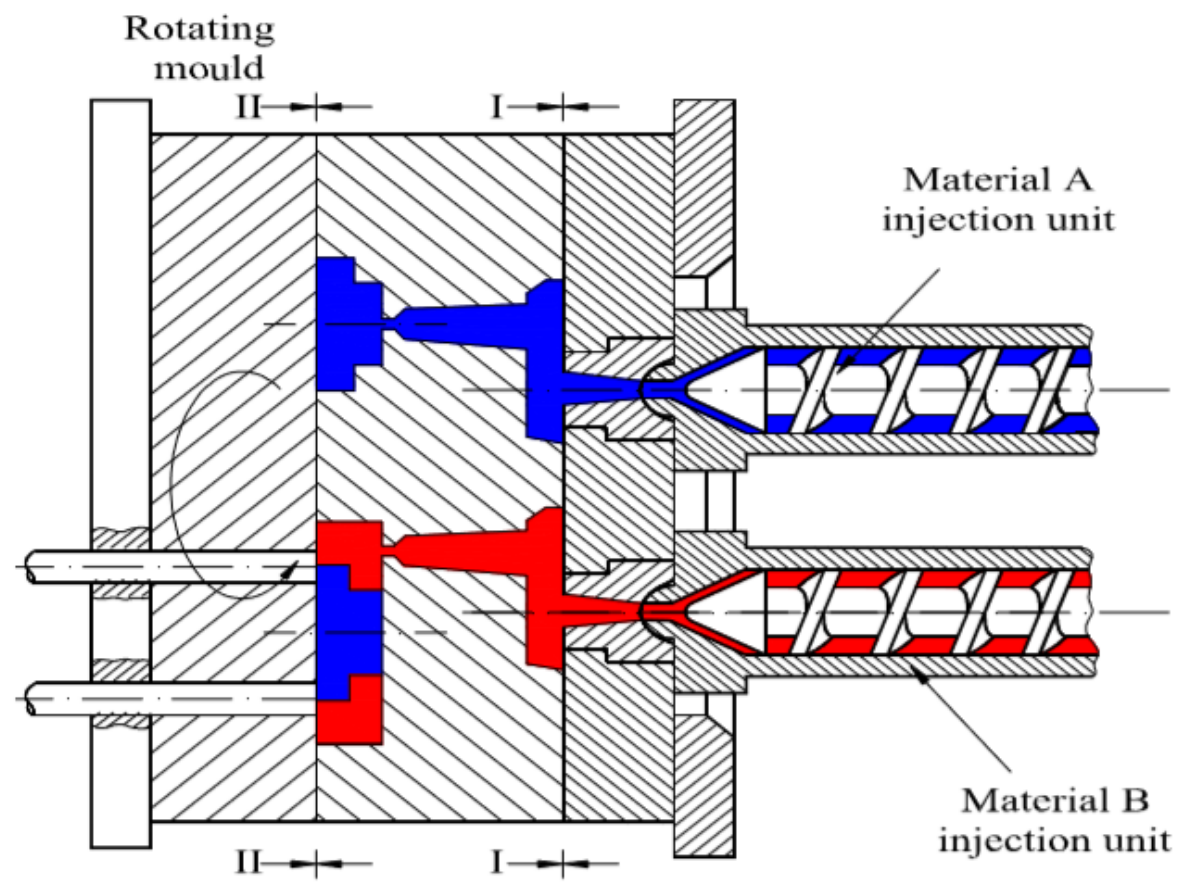

Figure 1. Schematic diagram of the two polymer moulds for the injection over-moulding process [23].

The potential of thermoplastic or elastomer injection over-moulding processes has attracted the attention of many researchers. Chen et al. (1994) studied multi-material injection moulding and bi-injection moulding processes using an amorphous polymer for the skin polymer and a second colour of the same polymer for the core. They investigated the melting 
flux evolution of both polymers and the distribution of skin and core materials in the final component [24]. Lee, Isayev, and White (1998) investigated the evolution of the interface between each phase of a sandwich structure during an injection moulding process. The final component was simulated using the Hele Saw approximation. In this model, the melting temperature, viscosity, and effects of the injection rate were considered [25]. Palluch and Isayev (2000) proposed a numerical method to simulate a bi-injection moulding process. They investigated the interface evolution and considered the causes of stress-induced crystallisation, elasticity effect, and transient movements at the interface during the biinjection process [26]. Liu et al. (2004) simulated the over-injection moulding process using C-Mold and Fortran software. They compared their experimental results with those obtained with a conventional injection moulding process. They concluded that in over-injection moulding, the fill time is shorter, and there is less difference in the flow rates of the materials with bi-injection moulding relative to a conventional injection moulding process [27].

In this study, we propose a method to improve numerical simulations of the bi-injection moulding process for producing standard peel test specimens. The thermo-rheo-kinetic behaviour is described by the kinetic model, the rheological constitutive equations, and the heat transfer during the injection moulding process. These specific behaviours were considered, and the proposed model was implemented by a finite element method using Cadmould3D software. Numerical results of the filling process were compared with biinjection tests to validate the performance of the proposed model and the identified parameter sets. The numerical data are in good agreement with the two-component bi-injection experiments.

\section{Materials and experimental procedure}

\subsection{Materials}

LSR rubber materials used in this work were supplied by Bluestar Silicones, systems Silbione (LSR4350, LSR4370, and TCS7550). These materials are characterised by specific properties: ultra-low durometer values, fast curing at high temperature, low thermal conductivity, good capacity for self-lubrication, and easy over-moulding processing with shorter cycle times.In our tests, the PA66GF30 black polyamide is a $30 \%$ glass fibrereinforced, high-temperature stabilised composite with excellent mechanical properties. Bex et al. (2019) concluded that this polyamide material is often chosen due to a low shrinkage 
value that facilitates the adhesion process at the interface of two-component, injectionmoulded materials [13].

The thermal and mechanical properties and typical applications of each material used in this study are summarised in Tables 1 and 2. Several characterisations of these silicone-based elastomers under high strain, uniaxial or multiaxial loading, and static or cyclic loading conditions have been performed by Bernardi et al. (2017). They developed methodologies to predict fracture properties that are critical to elastomer performance [28-29]. Methods to characterise the cyclic stress-stretch responses of elastomer and composite materials were developed by Xiang et al. (2020) to quantify interface adhesion for multi-component materials $[30]$.

\begin{tabular}{cccc}
\hline $\begin{array}{c}\text { Liquid silicone } \\
\text { rubber }\end{array}$ & $\begin{array}{c}\text { Density } \\
\left(\mathbf{g} \cdot \mathbf{c m}^{-3}\right)\end{array}$ & $\begin{array}{c}\text { Hardness } \\
\text { score A }\end{array}$ & $\begin{array}{c}\text { Mix ratio } \\
\text { A/B }\end{array}$ \\
\hline LSR4350 & 1.12 & 50 & $1: 1$ \\
LSR4370 & 1.14 & 68 & $1: 1$ \\
TCS7550 & 1.25 & 52 & $1: 1$
\end{tabular}

Table 1. Mechanical properties of LSR and TCS rubber materials.

\begin{tabular}{lc}
\hline Polyamide & PA 66 - GF 30 \\
\hline Density $\left(\mathbf{g} \cdot \mathbf{c m}^{-3}\right)$ & 1.14 \\
Melting temperature $\left({ }^{\circ} \mathbf{C}\right)$ & 220 \\
Tensile modulus $(\mathrm{MPa})$ & 9500 \\
Stress at fracture $(\mathrm{MPa})$ & 190 \\
Thermal conductivity $\left(\mathbf{W} \cdot \mathbf{m K}^{-\mathbf{1}}\right)$ & 0.183 \\
Specific heat capacity $\left(\mathbf{J} \cdot \mathbf{k g}^{-1} \cdot \mathbf{K}^{-\mathbf{1}}\right)$ & 2700 \\
\hline
\end{tabular}

Table 2. Thermal physical properties of the polyamide.

\subsection{Differential scanning calorimetry (DSC)}

Cross-linking reactions were performed by DSC (Setaram DSC92). A standard test method for evaluating elastomers by DSC (ASTM D7426-08) was applied. Before testing, the specimen temperature was stabilised at room temperature for $2 \mathrm{~min}$ and then raised to $160{ }^{\circ} \mathrm{C}$ at heating rates ranging from 1 to $20{ }^{\circ} \mathrm{C} / \mathrm{min}$. The mass of each sample ranged from 40 to 70 mg. Experiments were performed in triplicate, and the experimental data for shear stress of LSR and TCS materials was expressed as the mean $\pm 3 \%$.

Cross-linking rates are related to the heat given off during the exothermic reaction due to vulcanisation [31]. An environmentally friendly curing system was recently developed by 
Dziemidkiewicz et al. (2020) in which the cross-linking mechanism is a Heck-type reaction [32].

\subsection{Rheological measurements}

The flow behaviour and viscosity of LSR rubber and PA66 materials were investigated with shear controlled rotational measurements at shear rates from 1 to $10^{2} \mathrm{~s}^{-1}$. A standard test method for evaluating the rheological flow properties of elastomer materials (ASTM D760511) was applied. Rheology experiments were performed using a rotational rheometer (HAAKE MARS III) coupled with HAAKE RheoWin software (ThermoFisher Scientific). A cone-plate geometry configuration was selected with a $35-\mathrm{mm}$ diameter cone and plate geometry with a $2^{\circ}$ angle. Rheological tests of LSR rubber materials were carried out in two

parts (A and B) without a platinum catalyst at a constant temperature close to the ambient temperature of the testing laboratory. In addition, rheological studies were supplemented using a capillary Rosand RH2000 rheometer and performed at shear rates ranging from $10^{2}$ to $10^{5} \mathrm{~s}^{-1}$. The geometry of the die was $0.5 \mathrm{~mm}$ in diameter and $16 \mathrm{~mm}$ in length. Rheological tests were performed in triplicate, and the data for cure degree and cure rate were expressed as the mean $\pm 0.5 \%$.

\subsection{Characterisation of curing kinetics}

The effects of temperature on the curing kinetics of different LSR rubber materials were investigated under identical conditions. Curing tests were conducted with oscillatory measurements using a rotational HAAKE MARS III rheometer. Experiments were carried out at a frequency of $1 \mathrm{~Hz}$, with an applied deformation of $1 \%$. Experiments were conducted at temperatures ranging from 25 to $140{ }^{\circ} \mathrm{C}$ by using a rotational parallel-plate mode. The dimensions of the trays used to characterise curing kinetics were $20 \mathrm{~mm}$ in diameter and 0.5 $\mathrm{mm}$ in thickness. The values of the storage modulus $\left(\mathrm{G}^{\prime}\right)$ and loss modulus $\left(\mathrm{G}^{\prime \prime}\right)$ were obtained and used to identify sets of curing kinetic parameters by the inverse method.

\subsection{Bi-injection moulding process}

The experimental setup employed for manufacturing two-component materials by thermoplastic and elastomeric injection moulding combined a thermoplastic injection moulding press coupled to an external control unit dedicated to elastomeric materials. A dedicated mould for two-component injection moulding was used, and the polyamide was injected into the first die cavity. After sequential movement in the mould, the moulded 
polyamide component was transferred the second cavity, where the over-moulding of LSR onto the polyamide substrate was performed (see Fig.2). The injection moulding process parameters employed for PA66 and LSR during the two-component injection moulding process are summarised in Table 3. Injection-moulding benchmark tests were used to validate the constitutive material behaviour and associated finite element simulations.
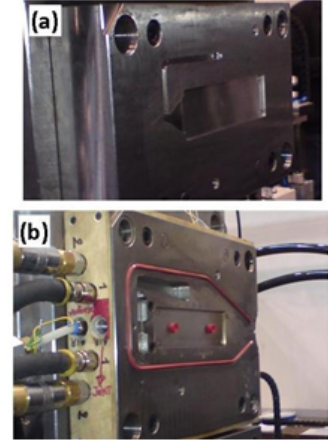
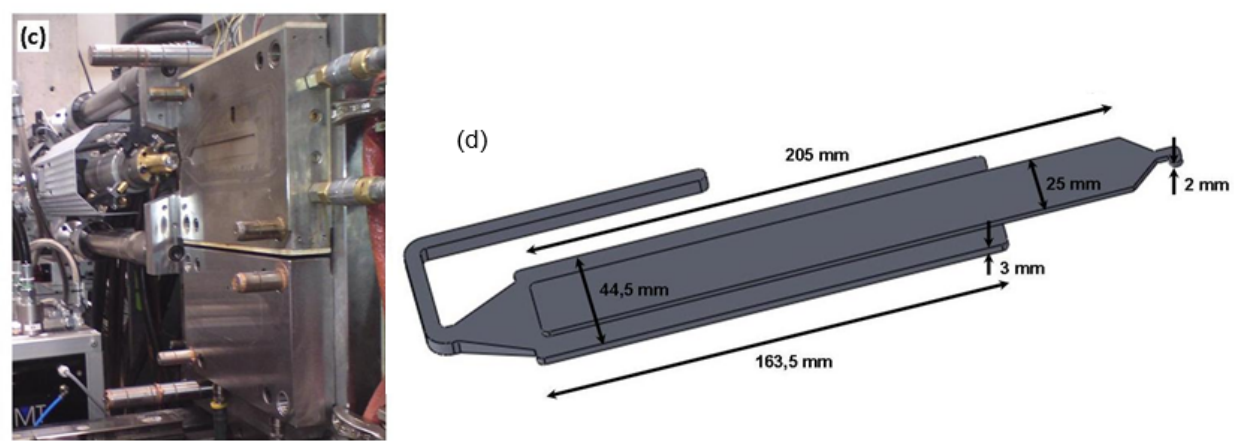

Figure 2. (a) Gate, runner, and mould cavity for the injection of polyamide, (b) View of the ejector and vacuum systems of the mould apparatus, (c) View of the second cavity for the LSR over-moulding, (d) Diagram of the standard peel test specimen geometry for the PA 66/LSR combination.

\begin{tabular}{lcc}
\hline Process parameters & $\begin{array}{c}\text { Injection parameters } \\
\text { (PA66) }\end{array}$ & $\begin{array}{c}\text { Injection parameters } \\
\text { (LSR) }\end{array}$ \\
\hline Mould temperature $\left({ }^{\circ} \mathrm{C}\right)$ & 80 & 180 \\
Melt temperature $\left({ }^{\circ} \mathrm{C}\right)$ & 245 & 20 \\
Packing pressure $(\mathrm{MPa})$ & 35 & 11 \\
Cooling time $(\mathrm{s})$ & 60 & - \\
Heating time $(\mathrm{s})$ & - & 60 \\
Holding time $(\mathrm{s})$ & 10 & 1.2 \\
\hline
\end{tabular}

Table 3. Two-component injection moulding parameters used to fabricate the PA66/LSTR peel test specimens.

\section{Experimental results and discussion}

\subsection{Cross-linking reaction}

The degree of cross-linking $(\alpha)$ during the chemical reaction is calculated based on experimental measurements of physicochemical and thermo-mechanical changes [33-35]. Various thermal profiles, ranging from 1 to $20^{\circ} \mathrm{C} / \mathrm{min}$, are used to determinate the peak of the exothermic cross-linking reaction by plotting the curves for the degree of cure and cure rate versus temperature, and the obtained data are illustrated in Figs.3 and 4, respectively.

The curves of cure rate and degree of cure versus temperature exhibited shifts caused by the effect of the thermal profile applied. Faster heating generated a more extensive range of heat flow. The results observed in this study are consistent with those reported in the literature [36-37]. 


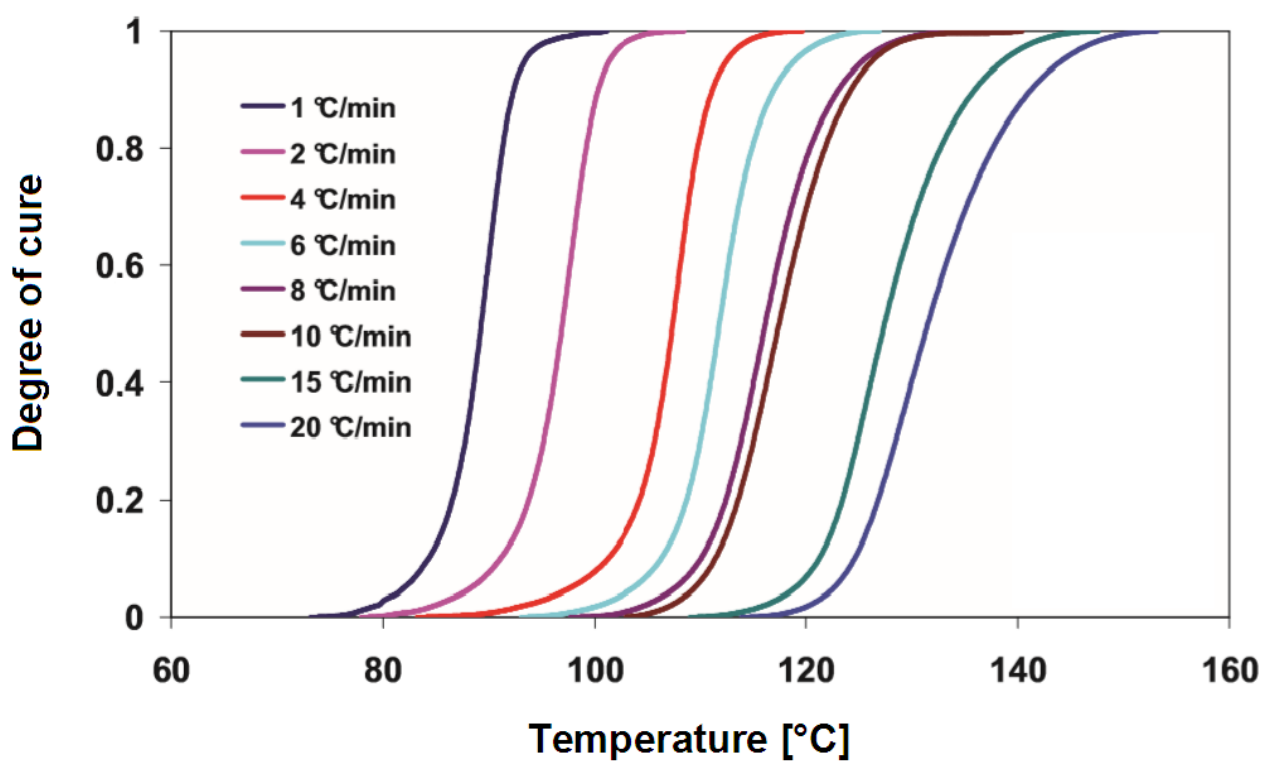

Figure 3. Degree of cureversus temperature measured by DSC at various thermal profiles.

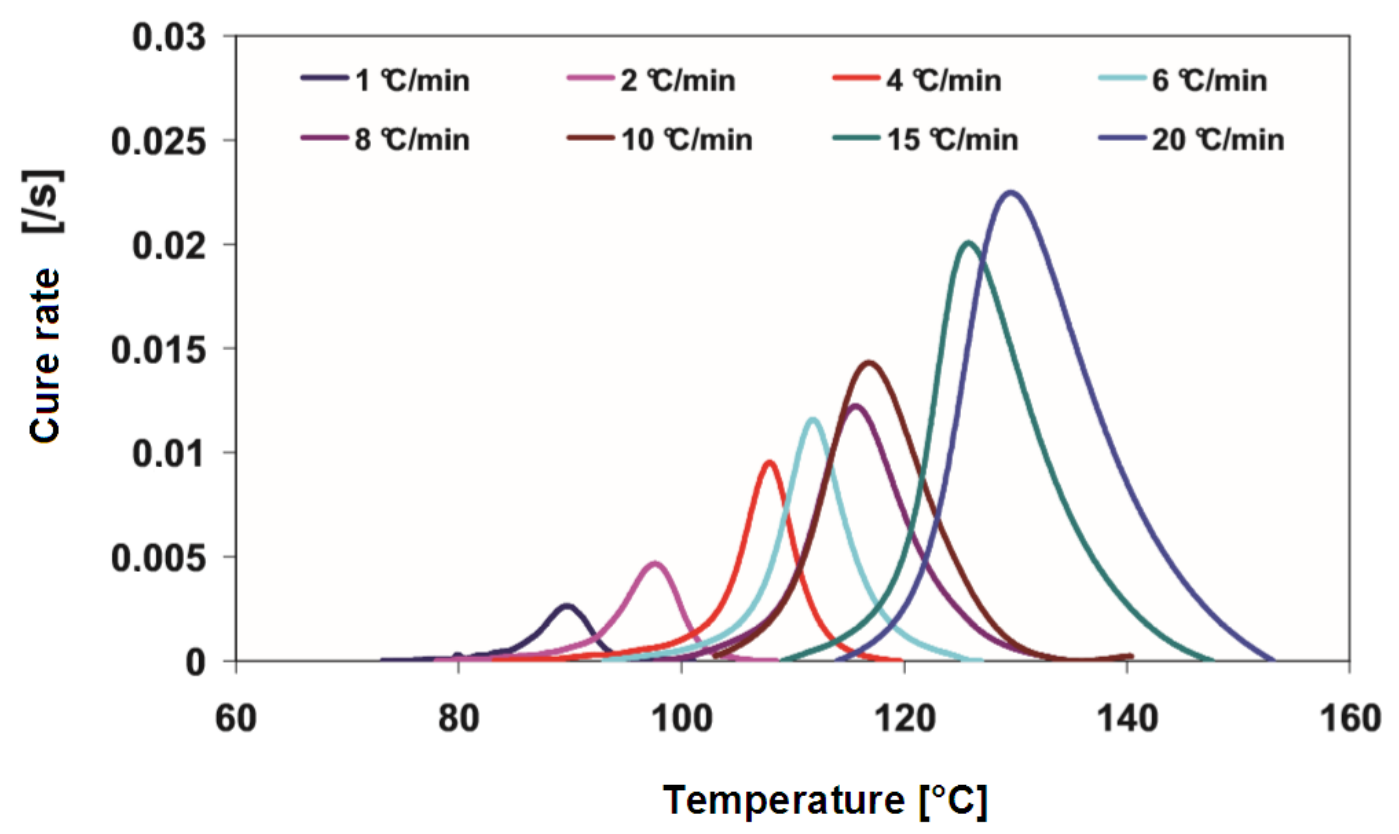

Figure 4. Cure rates versus temperature measured by DSC at various thermal profiles.

\subsection{Rheology tests}

The experimental curves of shear stress and shear viscosity versus shear rate are shown in Figs 5 and 6, respectively, for LSR and TCS materials. Shear behaviour occurs with an increase in the shear rate. Rheology tests at ambient temperature reveal that the two ingredients of LSR (4350A, 4350B, 4370A, and 4370B) have the same non-Newtonian flow and exhibit pseudo-plastic rheological behaviour (see Fig.5). Moreover, the two ingredients of TCS (7550A and 7550B) exhibit Newtonian behaviour at ambient temperature. 
Data from rheogram tests to evaluate the relationship between shear viscosity and shear rate for the elastomer material LSR4350A at various temperatures ranging from 25 to $100{ }^{\circ} \mathrm{C}$ are plotted in Fig.6. The obtained results reveal that the material exhibits pseudo-plastic rheological behaviour.
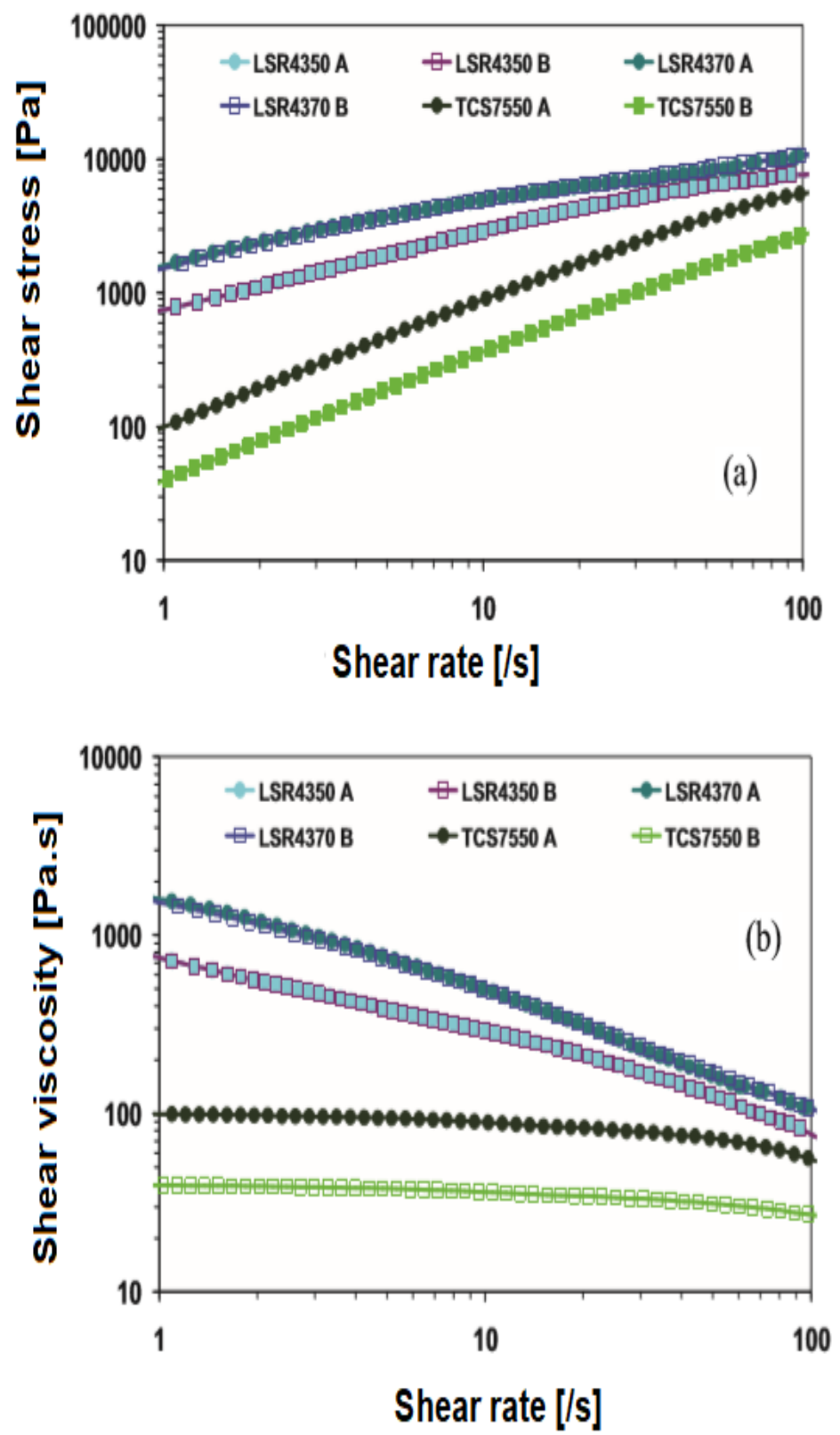

Figure 5. Rheogram tests of the two ingredients (A/B) of the LSR and TCS materials: a) shear stress versus shear rate and b) shear viscosity versus shear rate. 


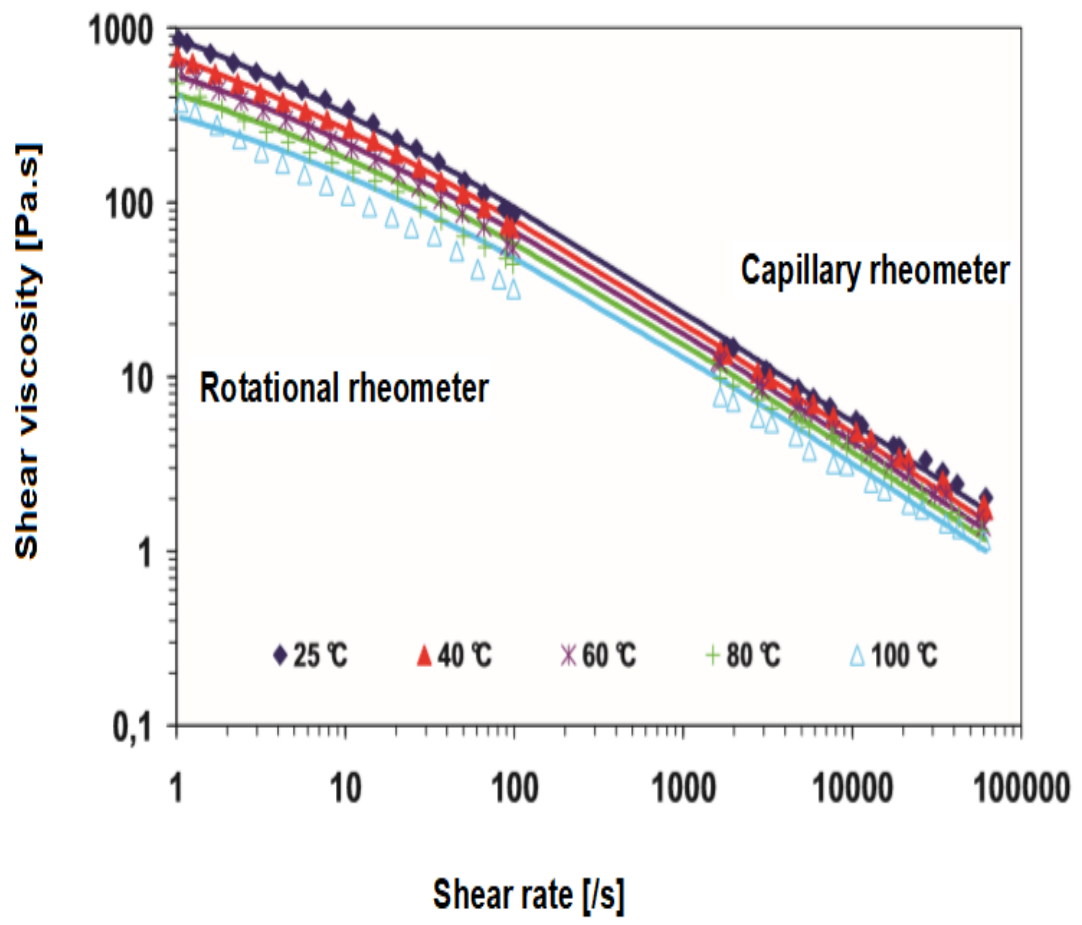

Figure 6. Experimental curves of shear viscosity versus shear rate include a wide range of shear rates (1 to $10^{5} \mathrm{~s}^{-1}$ ) and are performed at temperatures ranging from 25 to $100{ }^{\circ} \mathrm{C}$ for the elastomer material LSR4350A.

\subsection{Curing measurements}

Full cycles of curing versus time at different temperatures for the LSR4350 material are shown in Fig.7a. At the start of vulcanisation, the silicone hardens slowly and corresponds to the liquid phase of the rubber. It then increases progressively with time and temperature to approach a value of 1 . Vulcanisation is affected substantially by temperature. The curing kinetic curves of LSR4350, LSR4370, and TCS7550 materials obtained at $100{ }^{\circ} \mathrm{C}$ are illustrated in Fig.7b. The vulcanisation cycle can be divided into three distinct phases: induction, curing, and reversion. During the induction phase, the degree of cure is almost zero and increases slowly; i.e., corresponding to the liquid phase of the rubber. The reaction then proceeds quickly to a second plateau corresponding to the elastic-solid phase of the silicone. This intermediary phase corresponds to the beginning and end of vulcanisation. The vulcanisation reaction occurs more rapidly with LSR4350 silicone than the two other elastomers (LSR4370 and TCS7550). 

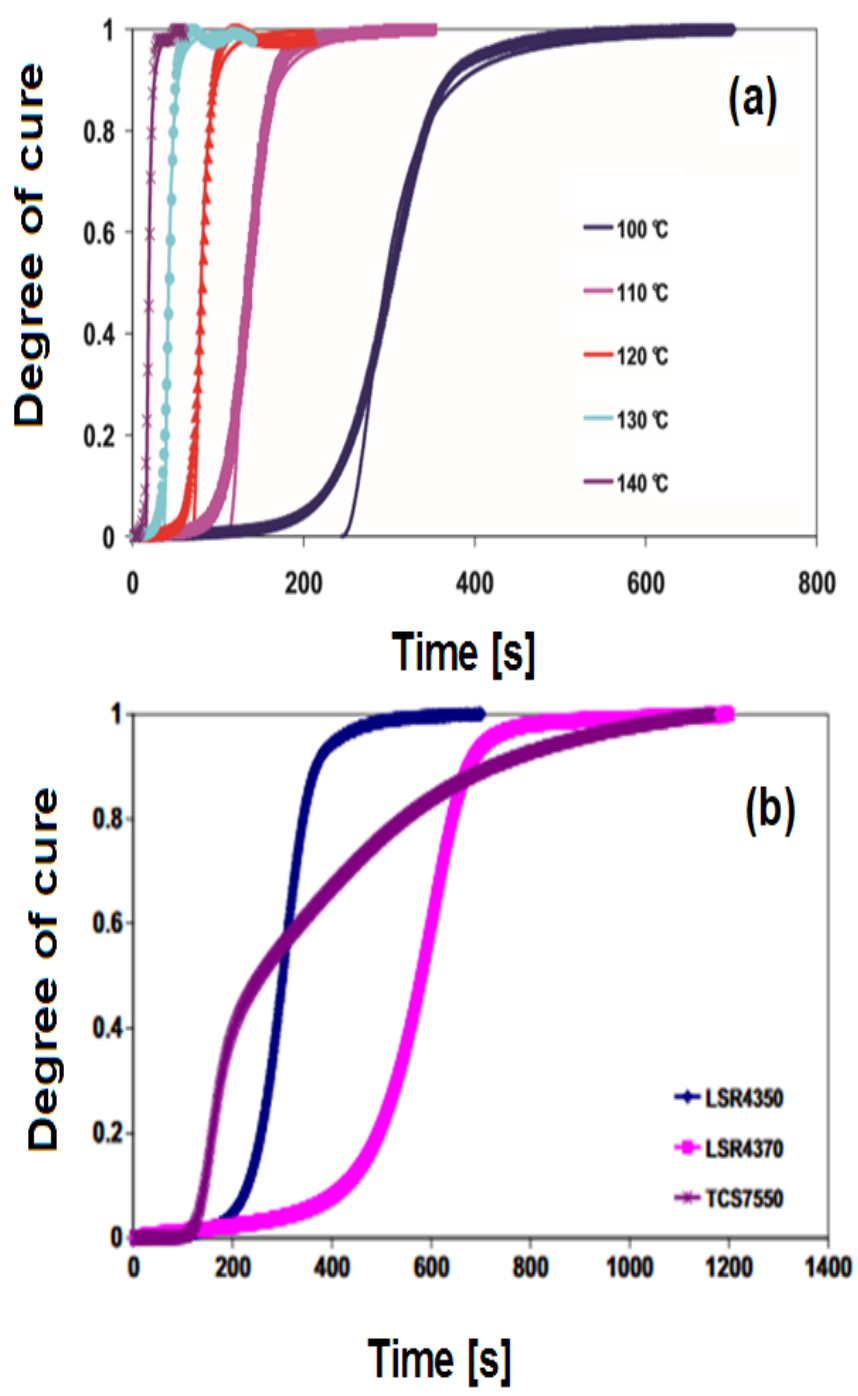

Figure 7. Experimental data of full cycles of curing versus time obtained at (a) various temperatures with LSR4350 and (b) $100{ }^{\circ} \mathrm{C}$ with the indicated liquid silicone rubber materials.

\subsection{Injection moulding process}

Bi-injection moulding of PA6/LSR4350 peel test specimens was conducted in two stages: (i) The PA66 polymer was initially injected under a pressure of 470 bar at $240{ }^{\circ} \mathrm{C}$. The mould was then heated to $80{ }^{\circ} \mathrm{C}$, and the PA66 sample was manually inserted into the second cavity that was dedicated to LSR injection. (ii) The over-moulding of LSR4350 onto the PA66 samples was conducted at ambient mould temperature for $3 \mathrm{~s}$. The peel test specimens were removed from the mould after vulcanisation for $40 \mathrm{~s}$ (see Fig.8).

The analysis of LSR-polyamide moulded peel test specimens reveal good adhesion. No deformation is observed at the interface because shrinkage of the polyamide during the first 
injection is low and the optimised heating parameters provide a full cycle of LSR curing at the interface between the two materials. A specific mould instrument that is designed for twocomponent injection moulding of elastomer and polyamide materials was used in this study. The injection tests were performed with multiple thermocouples placed at different locations to measure temperature distribution and monitor process parameters for industrial product quality and finite element model validation.

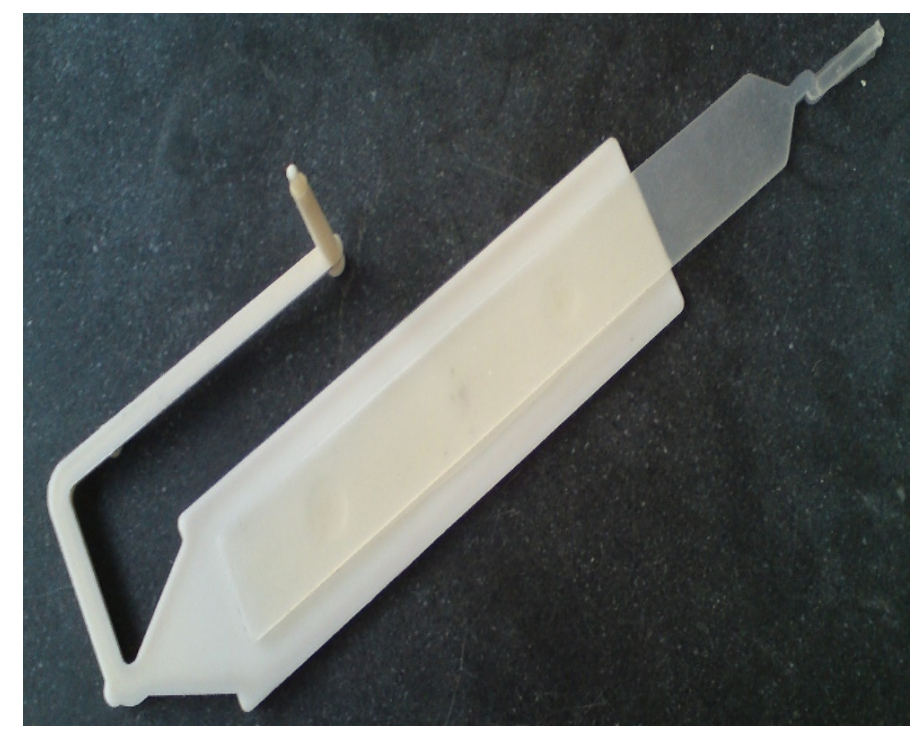

Figure 8. Over-mould of the PA66/LSR4350 peel test specimen.

\section{Numerical simulation and discussion}

\subsection{Viscosity model}

The rheological constitutive equations are modelled using the Carreau-Yasuda and Williams-Landel-Ferry (WLF) viscosity models that describe the non-Newtonian flow properties of the polymer. The Carreau-Yasuda model provides simplified governing equations for non-isothermal and non-Newtonian viscous fluids to describe the evolution of shear viscosity behaviour versus shear rate [38] as follows:

$$
\eta(\dot{\gamma}, T)=\eta_{0}(T)\left(1+\left(\frac{\eta_{0}(T) \dot{\gamma}}{\tau}\right)^{a}\right)^{\frac{n-1}{a}}
$$

where $\eta$ is the shear viscosity $(\mathrm{Pa} \cdot \mathrm{s}) ; \eta_{0}$ is the zero shear rate shear viscosity or the Newtonian limit, in which viscosity approaches a constant at very low shear rates $(\mathrm{Pa} \cdot \mathrm{s}) ; \dot{\gamma}$ is the shear rate $\left(\mathrm{s}^{-1}\right) ; T$ is the temperature; $\tau$ represents the critical shear stress from the Newtonian plateau; $a$ is a parameter to describe the transition region between the zero shear rate and 
power-law regions; $n$ is the power law index in the high shear rate regime $(n<1$ represent shear thinning, $n>1$ represent shear thickening, and $n=1$ represents Newtonian flow above the critical yield stress).

In this study, temperature dependence was defined using the WLF model [39], which is an empirical equation associated with time-temperature superposition. This relationship is usually expressed as follows:

$$
\log \left(\alpha_{T}\right)=\log \left(\frac{\eta_{0}(T)}{\eta_{0}\left(T_{0}\right)}\right)=-\frac{C_{1}\left(T-T_{0}\right)}{C_{2}+\left(T-T_{0}\right)}
$$

where $\alpha_{T}$ is the shift factor; $\eta_{0}(T)$ and $\eta_{0}\left(T_{0}\right)$ are shear viscosities at temperature $T$ and reference temperature $T_{0}$, and the reference temperature is chosen to construct the compliance master curve; $C_{1}$ and $C_{2}$ are empirical material-specific constants (not temperature-dependent) that are adjusted to fit the values of the superposition parameter.

The model parameter values identified by the inverse method of least square fit to obtain the best fit with the experimental rheological data for the Carreau-Yasuda and WLF models are summarised in Table 4. The comparative analysis of the shear viscosity versus imposed shear rate is illustrated in Fig.9. The rheological data estimated using the Carreau-Yasuda and WLF models are in good agreement with the experimental results, indicating that the rheologic parameters of the elastomeric materials predicted by these models are accurate.

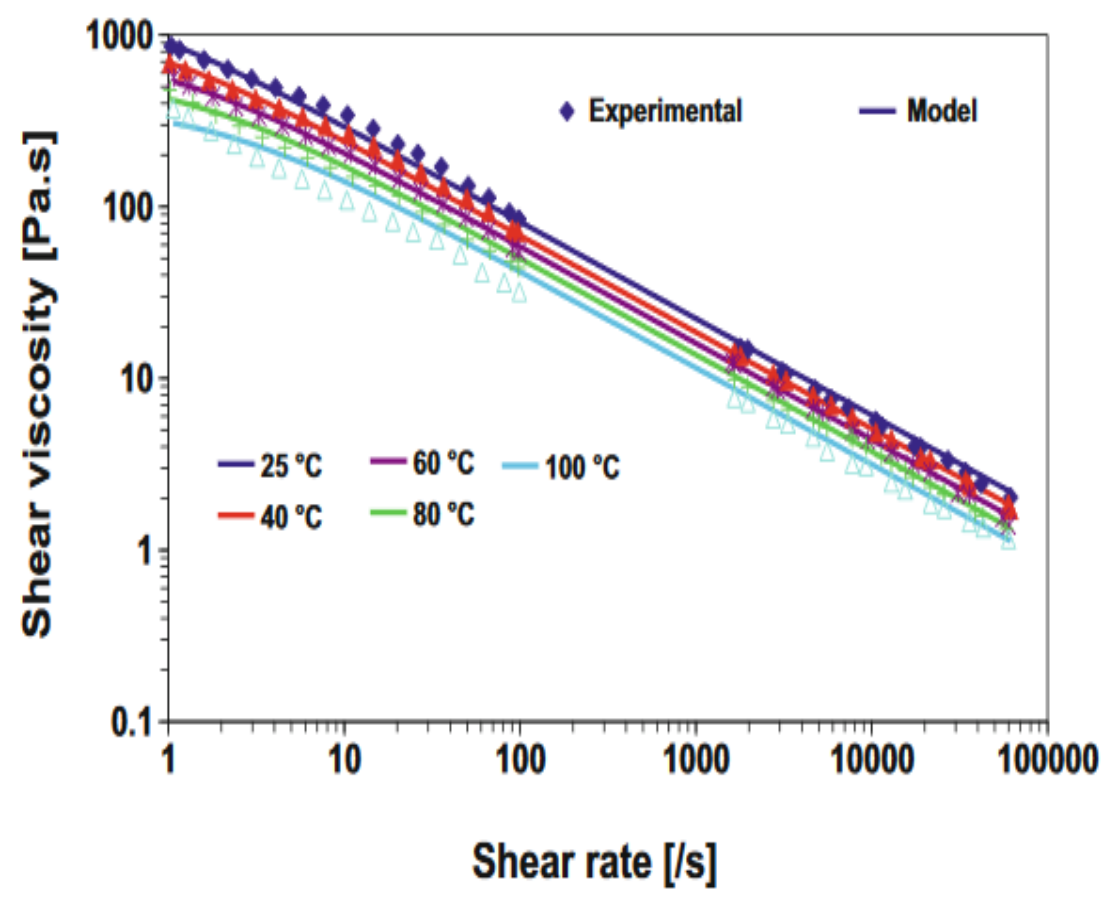


Figure 9. Shear viscosity versus shear rate at different temperatures and the fitting curves of Carreau-Yasuda and WLF models for the LSR4350 material.

\begin{tabular}{cccccc}
\hline Materials & $T_{0}\left({ }^{\circ} \mathrm{C}\right)$ & $C_{1}$ & $C_{2}(\mathrm{~K})$ & $\eta_{0}\left(T_{0}\right)($ Pa.s $)$ & $a$ \\
\hline LSR4350 & 25 & 4.30 & 428.92 & 3390.73 & 0.39 \\
LSR4370 & 25 & 70.80 & 6861.20 & 27.019 & 0.28 \\
TCS7550 & 25 & 3.08 & 304.24 & 76.28 & 0.76
\end{tabular}

Table 4. Parameters identified with the Carreau-Yasuda and WLF models for LSR and TCS materials.

\subsection{Kinetic modelling}

The parameters of curing kinetics for the rubber materials were identified using the models proposed by Claxton and Liska [40] and Isayev and Deng [41]. These models are frequently used to predict curing kinetics. From the experimental data of the curing tests conducted with the Mars III rheometer, the degree of cure $(\alpha)$ is calculated by nonlinear regression.

$$
\alpha=\frac{G^{\prime}(t)-G_{\text {min }}^{\prime}}{G_{\text {max }}^{\prime}-G_{\text {min }}^{\prime}}
$$

where $G^{\prime}(t)$ is the elastic shear modulus at time t; $G_{\text {max }}^{\prime}$ is the maximum elastic modulus; $G_{\text {min }}^{\prime}$ is the minimum elastic shear modulus during the thermal curing process.

Experimental results of curing kinetics conducted at different temperatures (100 to $140{ }^{\circ} \mathrm{C}$ ) were compared with the numerical data computed by nonlinear regression using the IsayevDeng model (see Fig.10). The comparison between the predicted and experiment curves for LSR4350 shows excellent agreement, with an error estimated at $<2 \%$. The model predicts full curing times that are faster than the corresponding experimental data at various temperatures. The accuracy and applicability of the Isayev-Deng model were verified by comparing the numerical curing value versus time of the elastomer component with experimentally measured data. The same validation process was previously reported by Erfanian et al. (2016) [42]. 


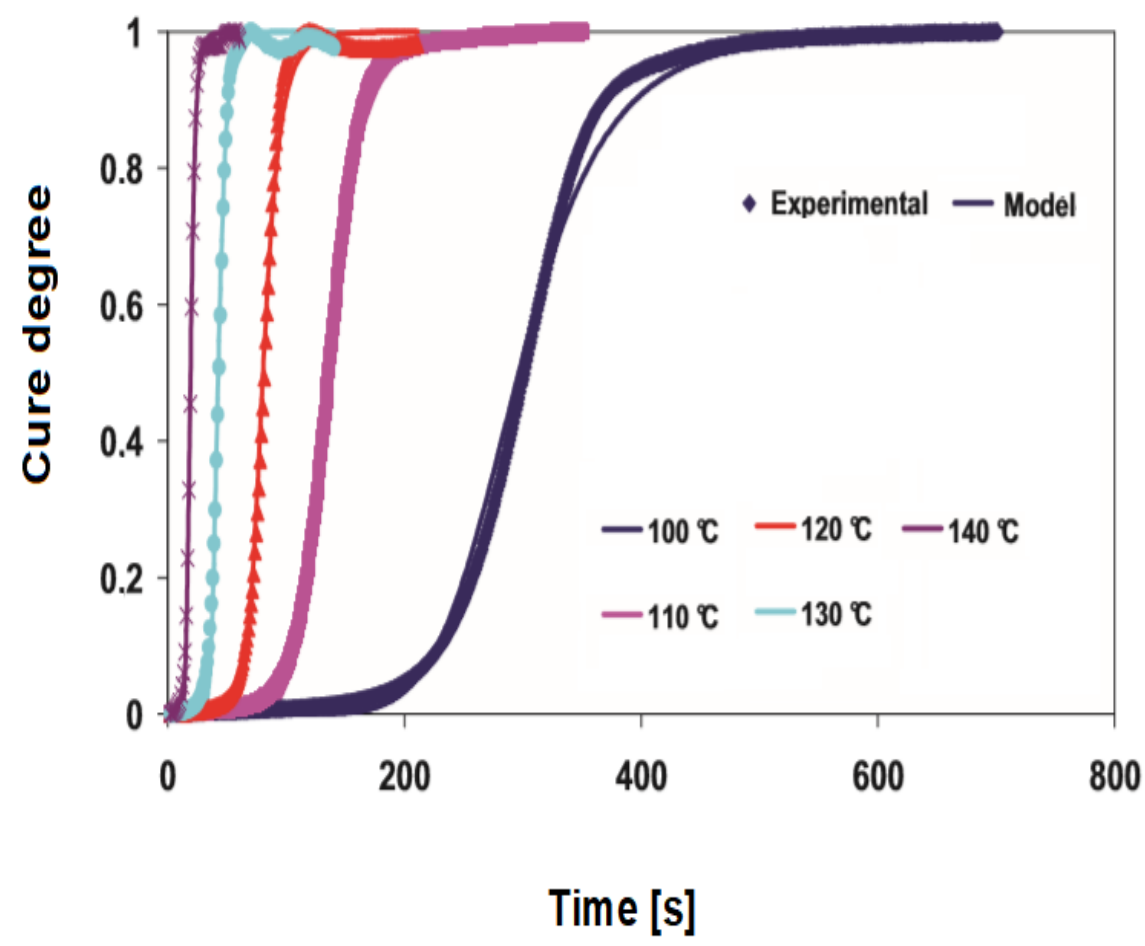

Figure 10. Comparison of the curing kinetics exhibited in experiments and those predicted by the Isayev-Deng model at the indicated temperatures for the LSR4350 material.

\subsection{Numerical simulations and discussion}

The adhesion and strength at the interface between the two components obtained by the over-moulding injection process is a significant factor in choosing material combinations for manufacturing two-component materials. The simulation of adhesion in the case of a tube with a rubber ring has been reported by Six et al. (2019) to predict the adhesion performance of a two-component material [43].

The components fabricated in this study were submitted to standard and normalised evaluation with ASTM rubber adhesion peel tests (ASTM C 794-18 standard test method for adhesion-in-peel of silicone elastomers). The description of the specimen geometry for the interface between the two materials (polyamide and LSR) is illustrated in Fig.11a. The finite element meshes of the two materials in the peel test component, corresponding to runners, gates, and sprues, are shown in Fig.11b. Over-moulding simulations have been used to analyse sequentially over-moulded parts composed of polyamide and LSR materials. Tables 1 and 2 present some properties of the considered materials. The injection process parameters applied in the over-moulding injection simulation are listed in Table 3. 
(a)

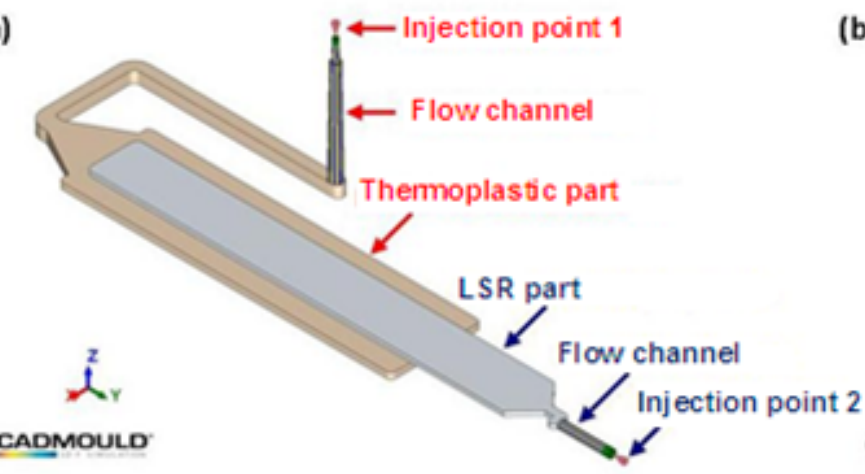

(b)

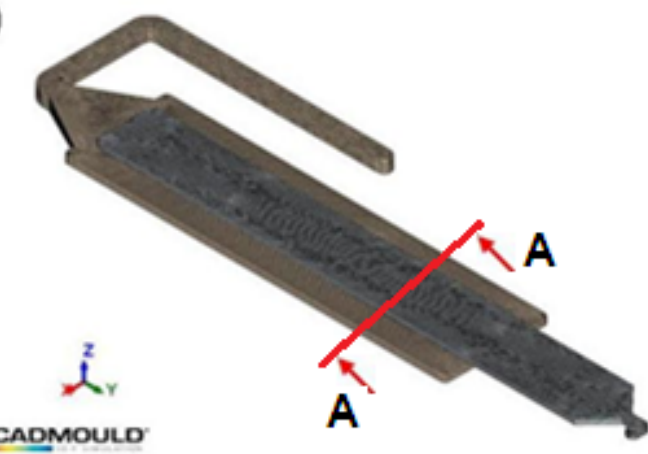

Figure 11. (a) Over-moulding injection peel test specimen for PA66/LSR materials. (b) A 3D mesh of the standard peel test with runners, gates, and sprues

Full filling of the 3D thermoplastic polyamide injected component is shown in Fig 12. The filling time was estimated at $1.2 \mathrm{~s}$ to ensure a complete filling of the mould die cavity. After the final mould filling, the temperature of the thermoplastic polyamide substrate is approximately $80{ }^{\circ} \mathrm{C}$ and the maximum temperature of $115^{\circ} \mathrm{C}$ is found in the gate area, as shown in Fig.12b.

These results are then used as a configuration reference for the over-moulding injection of bi-material peel test specimens. The evolution of the flow front during the over-moulding step of LSR rubber on the thermoplastic polyamide substrate is shown in Fig.12c. The final estimated filling time was approximately $5.4 \mathrm{~s}$, corresponding to the maximum temperature of $104{ }^{\circ} \mathrm{C}$, as shown in Fig.12d. This specific study and analysis were performed to validate whether the conditions chosen for the selected over-moulding injection process result in premature cutting during filling, which could block the flow and generate an incompletely filled part. 


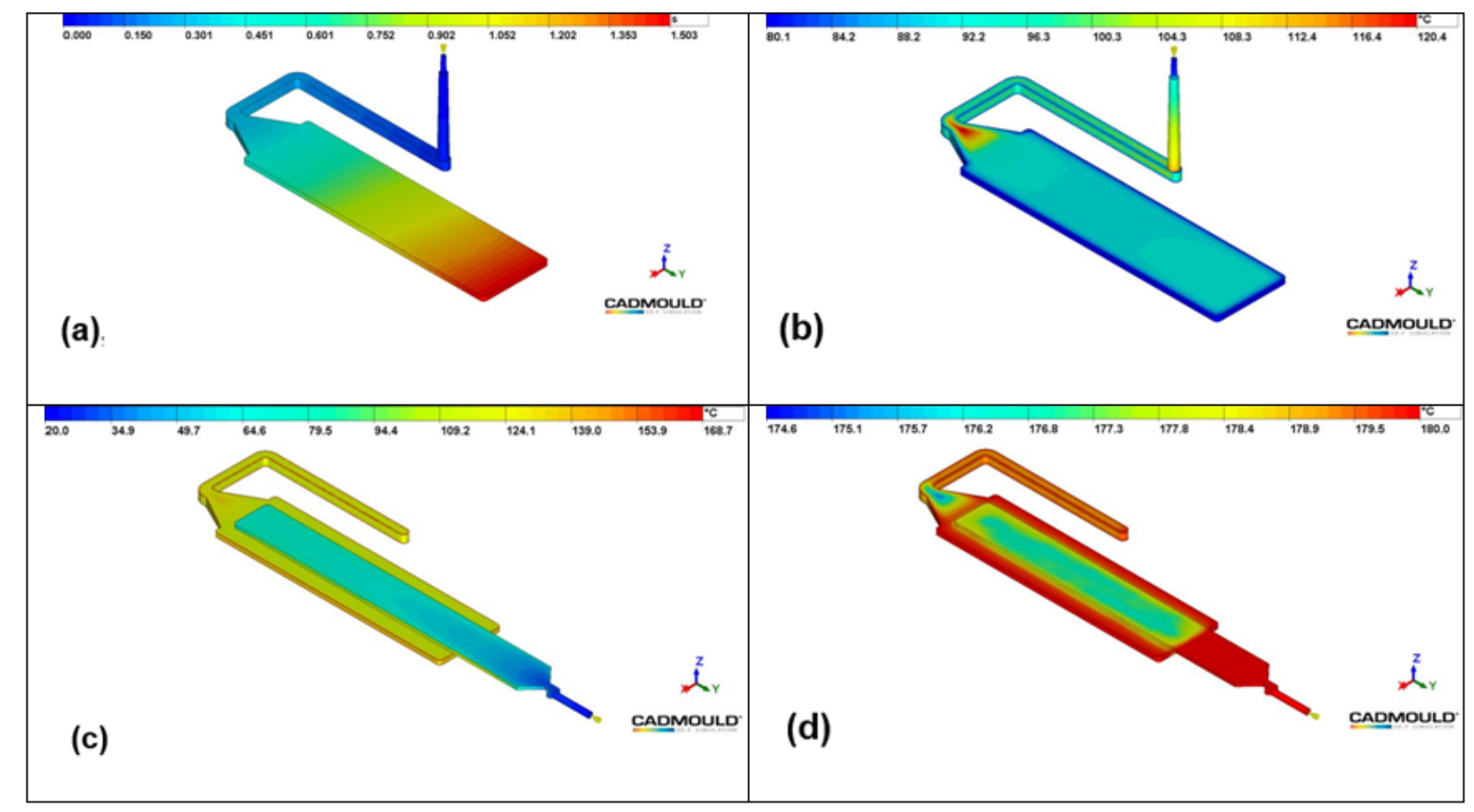

Figure 12. Numerical simulation showing the evolution of the flow front during filling and the temperature distribution at the end of filling for (a), (b) polyamide injection moulding, (c), (d) LSR over-moulding injection moulding.

The over-moulding injection simulation of rubber LSR4350 on a thermoplastic polyamide substrate was performed with an injection rate of $5 \mathrm{~cm}^{3} \cdot \mathrm{s}^{-1}$ and an injection temperature of $20^{\circ} \mathrm{C}$. In these numerical simulations, the temperature field distribution of the polyamide substrate has been considered from the results of the previous polyamide injection during over-moulding. The mould cavities were heated to $180{ }^{\circ} \mathrm{C}$, corresponding to the vulcanising temperature of the LSR material. The material front evolution versus the time predicted by the over-moulding simulation for different filling times is illustrated in Fig.13. These results show that the filling phase ends after $2.2 \mathrm{~s}$. A gradual increase in the temperature of the thermoplastic substrate after heat exchange by conduction with the walls of the mould cavities is also observed. 


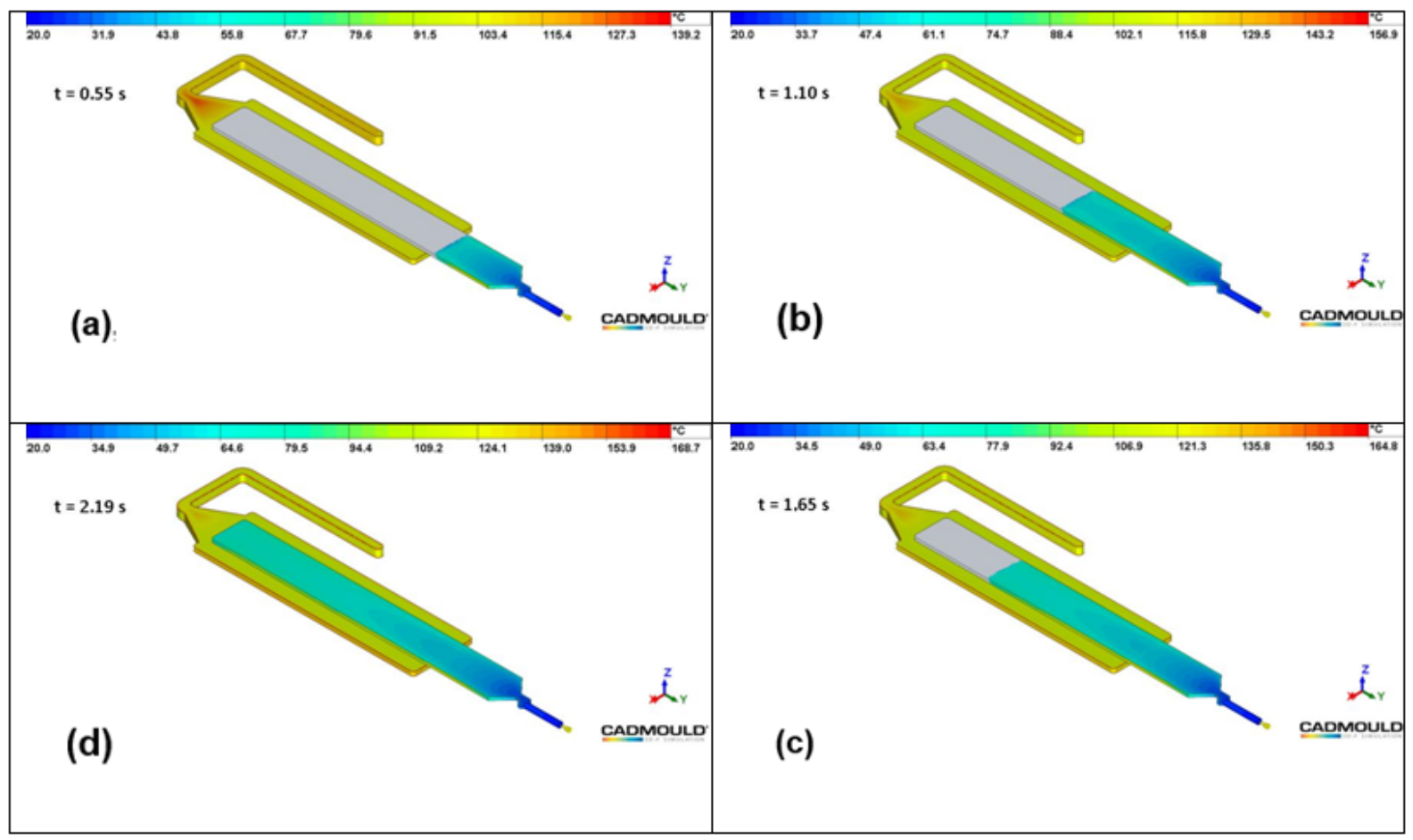

Figure 13. Evolution of the material front versus time obtained by the numerical simulation of over-moulding injection of LSR4350/PA66 for different filling times.

A sectional view of the middle of the peel test specimen illustrating the evolution of the temperature as a function of time was obtained. Sectional views of the standard peel test specimen illustrating the predicted temperature distribution inside the middle position are shown in Fig.14. The difference in the thermal conductivity between the polyamide polymer and the metallic die show that the temperature of the rubber specimen in contact with the sidewalls of the mould is higher than that in contact with the thermoplastic substrate. This phenomenon accelerates the vulcanisation kinetics on the exterior surface, as shown in Fig.14. 


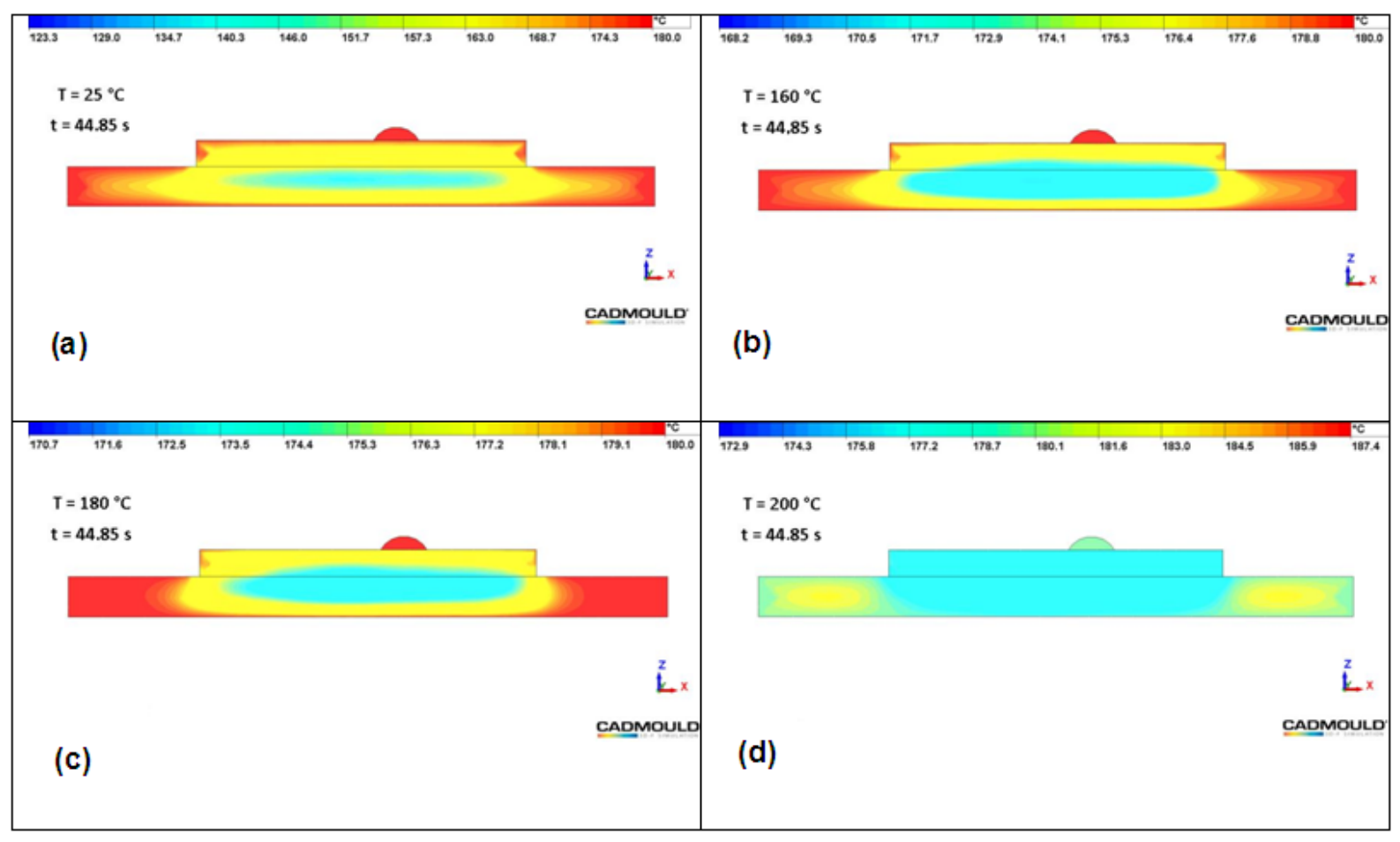

Figure 14. Numerical results of the temperature distribution during over-moulding injection obtained in the middle of the peel test specimen at different temperatures.

Distributions of the degree of cure during the over-moulding injection process were predicted at different times for the filling and heating stages and are shown in Fig.15. The sectional view is taken at the middle of the peel test specimen to illustrate the evolution of the degree of cure as a function of time. The value of the degree of cure at the end of the filling stage is almost zero and increases slowly but gradually during the heating period, as shown in Fig.15. The degree of cure distribution demonstrates the impact of temperature on curing kinetics. Notably, the area of the elastomeric material in contact with the mould sidewalls has a higher degree of cure, which is estimated to be $>99.6 \%$ at the end of the filling and heating stages, whereas that which is in direct contact with the thermoplastic substrate is approximately $97.5 \%$. 


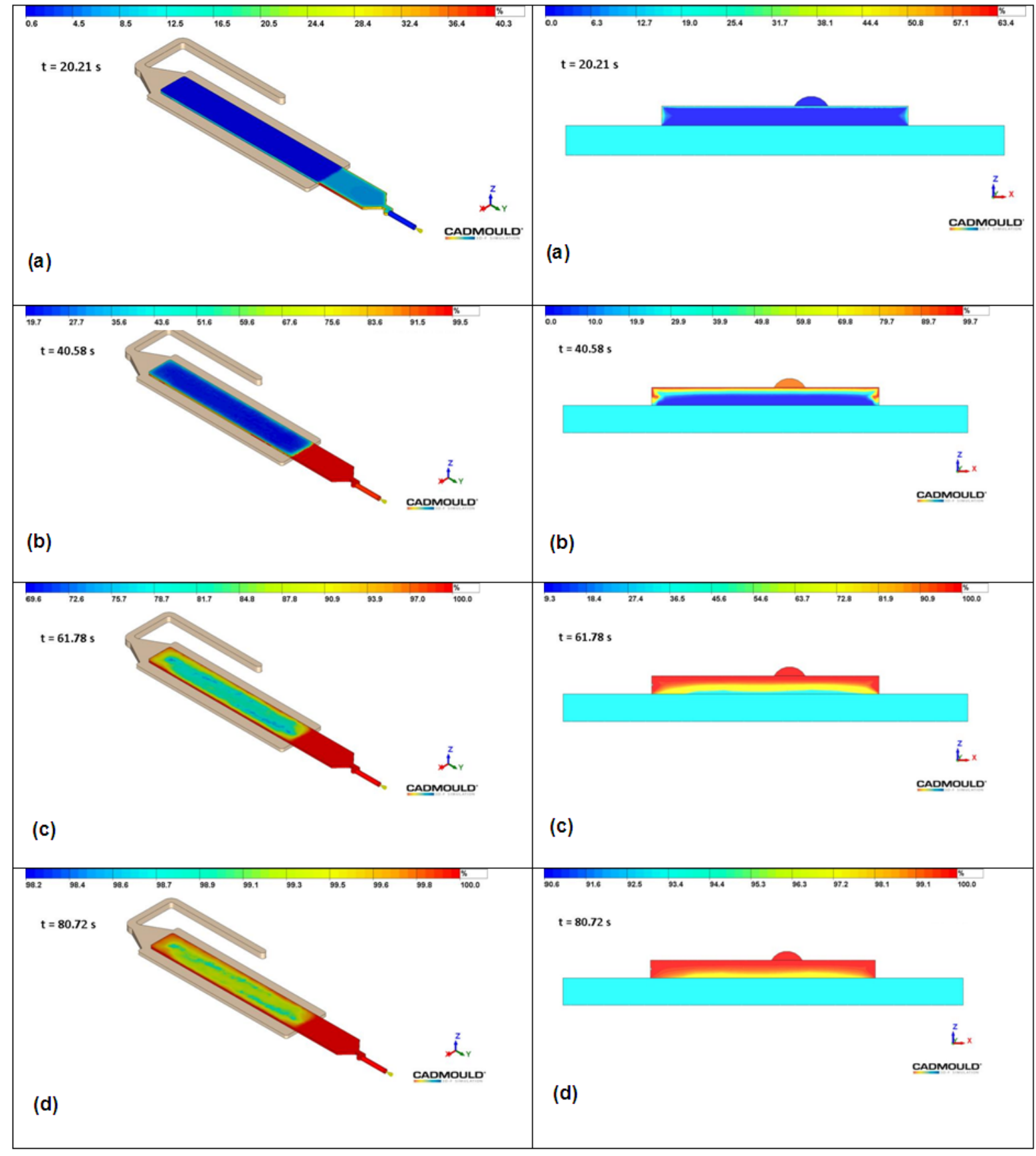

Figure 15. Numerical results of the degree of cure distributions at the end of the filling stage versus heating time for the LSR4350/PA66 at the middle of the standard peel test specimen.

\section{Experimental validation}

The method reported by Six et al. (2017) to compare the elastomer-thermoplastic injection sequence was used to validate the numerical simulation. A comparison between the experimental data of flow-front advancement and those predicted by the model was performed using the identified parameters of constitutive behaviour for rheological and cure 
kinetics during the filling stage, as shown in Fig.16. The accuracy of the simulation model during the over-moulding injection process exhibits a correlation with an error of $<3 \%$. The satisfactory agreement between the experimental data and numerical simulations reveals that the proposed method and identified prediction model are suitable for predicting the filling time of two-elastomer thermoplastic material injection moulding efficiently for manufacturing processes. Previous work by Bex et al. (2019) coupled the mechanical properties obtained by hardness measurements converted to the degree of cure have been optimised for numerical adhesion interface quality to predict mechanical properties of the fabricated component.
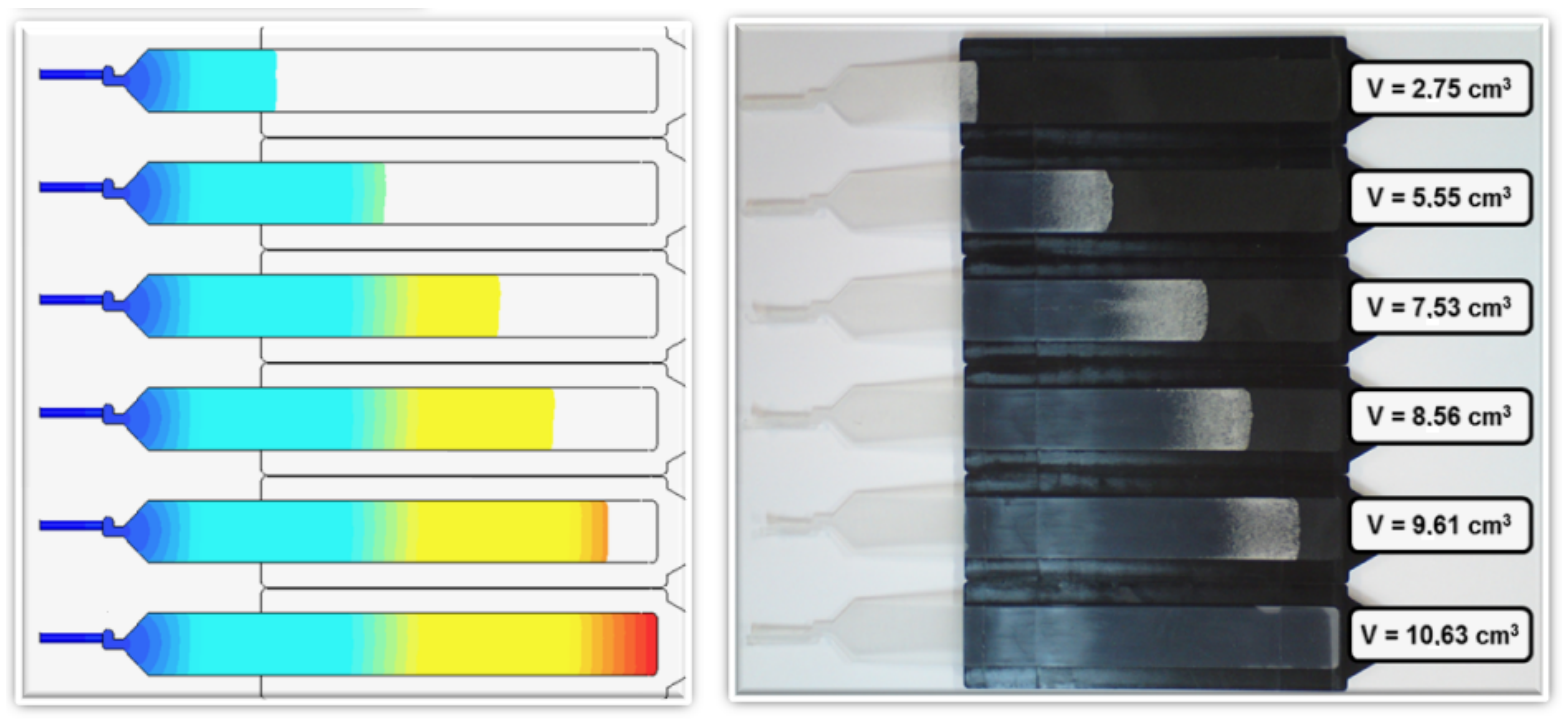

Figure 16. Comparison between the predicted and experiment flow-front measurements of the LSR material injected at different filling volumes in over-moulding injection tests.

\section{Conclusions}

In this study, LSR/PA66 over-moulding is investigated under industrial forming conditions to identify key factors that affect the quality of adhesion in the final product. Parameters measured by DSC, capillary rheometer, and rotational rheometer were used to identify a model dedicated to performing LSR/PA66 over-moulding simulations under controlled conditions. The Carreau-Yasuda and WLF model sappear to represent the rheological behaviours of elastomeric materials suitably over a wide shear range, and the Deng-Isayev model describes the curing behaviours of the same material sover a wide range of temperatures. 
Numerical models of over-moulding processes have been investigated to determine factors that affect the quality of adhesion at the interface between materials. The evolution of the filling and the cross-linking stages was studied, as well as the influence of temperature distribution on the degree of cure inside the elastomeric peel test specimen. Die mould cavities were designed and thermally controlled to reproduce industrial conditions and to validate the finite element models. The mould filling was found to depend on material parameters and processing conditions in bi-injection moulding with thermoplastic and elastomeric materials.

The quantitative correlation between the experimental data and numerical results was found to be good. A comparison of flow-front measurements at different stages exhibits good correlation with an error of less than $3 \%$.

\section{References}

1. A.M. Harte, J.F.Mc. Namara, Over-injection of thermoplastic composites. II. Numerical simulation, Journal of Materials Processing Technology, 182 (2007) 21-27. https://doi.org/10.1016/j.jmatprotec.2006.06.017

2. C. Eloo, H. Wack, M. Schwarz, M. Landers, Device for non-disruptive taking of melt samples from a compounding process and direct injection molding, Polymer Testing 85 (2020) 106427. https://doi.org/10.1016/j.polymertesting.2020.106427

3. H. Schäfer, C. Pretschuh, O. Brüggemann, Reduction of cycle times in injection molding of PLA through bio-based nucleating agents, European Polymer Journal, 115 (2019) 6-11. https://doi.org/10.1016/j.eurpolymj.2019.03.011

4. M. T. Ramesan, Thermogravimetric analysis, flammability and oil resistance properties in natural rubber and dichlorocarbene modified styrene butadiene rubber blends, Reactive $\begin{array}{lllll}\text { and } & \text { Functional } & \text { Polymers, } & 59 & \text { (2004) }\end{array}$ https://doi.org/10.1016/j.reactfunctpolym.2004.02.005

5. M. Rafei, M.H.R. Ghoreishi, G. Naderi, Development of an advanced computer simulation technique for the modeling of rubber curing process, Computational Materials Science 47 (2009) 539. https://doi.org/10.1016/j.commatsci.2009.09.022 
6. A. Arrillaga, A.M. Zaldua, R.M. Atxurra, A.S. Farid, Techniques used for determining cure kinetics of rubber compounds,Eur. Polym. J., 43 (2007) 47834799.https://doi.org/10.1016/j.eurpolymj.2007.08.024

7. A. Harkous, G. Colomines, E. Leroy, P. Mousseau, R. Deterre, The kinetic behavior of Liquid Silicone Rubber: A comparison between thermal and rheological approaches based on gel point determination, Reactive and Functional Polymers, 101 (2016) 20-27. https://doi.org/10.1016/j.reactfunctpolym.2016.01.020

8. J. Zhao, Q. Zhao, L. Wang, C. Wang, B. Guo, C. B.Park, G. Wang, Development of high thermal insulation and compressive strength BPP foams using mold-opening foam injection molding with in-situ fibrillated PTFE fibers, European Polymer Journal, 98 (2018) 1-10. https://doi.org/10.1016/j.eurpolymj.2017.11.001

9. TH. Khang, ZM. Ariff, Mold filling simulation dependence on material data input for injection molding process of natural rubber compound, Carl Hanser Verlag GmbH \& Co. KG, International Polymer Processing. J Polym Process Soc 325 (2014) 331. https://doi.org/10.3139/217.2934

10. X. Ye, H. Liu, Y. Ding, H. Li, B. Lu, Research on the cast molding process for high quality PDMS molds. Microelectron Eng $86 \quad$ (2009) 310-313. https://doi.org/10.1016/j.mee.2008.10.011

11. E. Leroy, A. Souid, A. Sarda, R. Deterre, A knowledge based approach for elastomer cure kinetic parameters estimation, Polym. Test., 32 (2013) 9-14. https://doi.org/10.1016/j.polymertesting.2012.08.012

12. G. Bex, J. De Keyzer, F. Desplentere, A. Van Bael, Two - component injection moulding of thermoplastics with thermoset rubbers: process development, Conference paper in AIP conference proceedings, 1914, 120001 (2017). https://doie.org/10.1063/1.5016759

13. G. Bex, W. Six, J. De Keyzer, F. Desplentere, A. Van Bael, Two - component injection moulding of thermoplastics with thermoset rubbers: The effect of the mould temperature distribution, Conference paper in AIP conference proceedings, 2055, 080002 (2019). https://doie.org/10.1063/1.5084876

14. A. El Labban, P. Mousseau, J.L. Bailleul, R. Deterre, Optimization of thick rubber part curing cycles, Inverse Problems in Science and Engineering 18 (2010) 313. https://doi.org/10.1080/17415971003589517 
15. C. F. Antunes, A. V. Machado, M. van Duin, Morphology development and phase inversion during dynamic vulcanisation of EPDM/PP blends, European Polymer JournalVolume 47 (2011) 1447-1459. https://doi.org/10.1016/j.eurpolymj.2011.04.005

16. F. Dimier, N. Sbirrazzuoli, B. Vergnes, M. Vincent, Curing kinetics and chemorheological analysis of polyurethane formation, Polym. Eng. Sci., 44 (2004) 518-527. https://doi.org/10.1002/pen.20046

17. H. Ou, M. Sahli, T. Barriere and J. C. Gelin, Experimental characterisation and modelling of rheokinetic properties of different silicone elastomers, International Journal of $\begin{array}{lllll}\text { Advanced } & \text { Manufacturing } \quad \text { Technology, } & 92 \quad \text { (2017) }\end{array}$ https://doi.org/10.1007/s00170-017-0481-0

18. H. Ou, M. Sahli, T. Barrière, J. C. Gelin, Multiphysics modelling and experimental investigations of the filling and curing phases of bi-injection moulding of thermoplastic polymer/liquid silicone rubbers, International Journal of Advanced Manufacturing Technology, 92 (2017) 3871-3882. https://doi.org/10.1007/s00170-017-0425-8

19. T. Adachi. T. Kataoka. M. Higuchi, Predicting impact shear strength of phenolic resin adhesive blended with nitrile rubber, International Journal of Adhesion and Adhesives, 56 (2015) 53-60. https://doi.org/10.1016/j.ijadhadh.2014.07.010

20. T. Yokoyama, K. Nakai, Determination of the impact tensile strength of structural adhesive butt joints with a modified split Hopkinson pressure bar, International Journal of $\begin{array}{lllll}\text { Adhesion } & \text { and } & \text { Adhesives, } & 56 & \text { (2015) }\end{array}$ https://doi.org/10.1016/j.ijadhadh.2014.07.011

21. M. T Ramesan, G. Mathew, B. Kuriakose, R. Alex, Role of dichlorocarbene modified styrene butadiene rubber in compatibilisation of styrene butadiene rubber and chloroprene rubber blends, European Polymer Journal, 37 (2001) 719-728. https://doi.org/10.1016/S0014-3057(00)00157-9

22. A. Baldan, Adhesively-bonded joints in metallic alloys, polymers and composite materials: mechanical and environmental durability performance, J Mater Sci, 39 (2004) 4729-4797. https://doi.org/10.1023/B:JMSC.0000035317.87118.ab

23. C. Fetecau, D. V. Dobrea and I. Postolache, Overmolding injection molding simulation of tensile test specimen, International Journal of Modern Manufacturing Technologies ISSN, 2 (2010) 2067-3604. 
24. S.C. Chen, , Hsu, K.F., Huang, J.S., Observation of the polymer melt flow in injection molding process using co-injection molding technique, International Communications in Heat and Mass Transfer, 21(1994) 499-508. https://doi.org/10.1016/07351933(94)90049-3

25. D.J. Lee, A.I. Isayev, J.L. White, Simultaneous sandwich injection molding: simulation and experiment, Conference proceedings at ANTEC'98, Vol. 1. (1998)

26. K.P. Palluch, A.I. Isayev, Multicomponent injection molding. Part 1: Interface and microstructure development, Conference proceedings at ANTEC Vol. 1. (2000).

27. W. Liu, D. Yao, B. Kim, Two-material injection molding filling simulation, ANTEC (2004).

28. L. Bernadi, R. Hopf, A. Ferrari, A.E. Ehert, E. Mazza, On the large strain deformation of silicone-based elastomers for biomedical applications, Polymer testing, 58 (2017) 189198, https://doi.org/10.1016/j.polymertesting.2016.12.029

29. L. Bernadi, R. Hopf, A. Ferrari, A.E. Ehert, E. Mazza, On the cycli dformation behavior, fracture properties and cytotoxicity of silicone-based elastomers for biomedical $\begin{array}{lllll}\text { applications, } & \text { Polymer } & \text { testing, } & 60 & \text { (2017) }\end{array}$ https://doi.org/10.1016/j.polymertesting.2017.03.018

30. Xiang G., Wang Z., Yang C., Yao X., Wang Y., Suo Z, Stretchable and fatigue -resistant materials, Materials Today, 34 (2020) 7-16, https://doi.org/10.1016/j.mattod.2019.08.009

31. J.P. Hernandez-Ortiz, T.A. Osswald, Modeling processing of silicone rubber: liquid versus hard silicone rubbers, J. Appl. Polym. Sci., 119 (2010) 8. https://doi.org/10.1002/app.31995

32. Dziemidkiewicz A., Anyszka R., Blume A. and Maciejewska, Reaction mechanism of halogenated rubber crosslinking using a novel environmentally friendly curing system, Polymer testing, 84 (2020) 106354 https://doi.org/10.1016/j.polymertesting.2020.106354

33. S.W. Wong, K.C. Frisch, Studies of catalysed isocyanate reactions by high performance liquid chromatography Prog. Rubber Plast. Technol., 7 (1991) 243-270.

34. D.W. Brazier, G.H. Nickel, Z. Szentgyorgyi, Enthalpic analysis of vulcanization by calorimetry. thiuram monosulfide/sulfur vulcanization of NR, BR and SBR, Rubber Chem. Technol., 53 (1980) 160-175. https://doi.org/10.5254/1.3535026 
35. G.E. Decker, R.W. Wise, D. Guerry, An oscillating disk rheometer for measuring dynamic properties during vulcanization, Rubber Chem. Technol., 36 (1963) 451-458. https://doi.org/10.5254/1.3539572

36. T. Kousksou, A. Jamil, K. El Omari, Y. Zeraouli, Y. Le Guer, Effect of heating rate and sample geometry on the apparent specific heat capacity: DSC applications, Thermochim. Acta, 519 (2011) 59-64. https://doi.org/10.1016/j.tca.2011.02.033

37. E. Leroy, A. Souid, A. Sarda, R. Deterre, A knowledge based approach for elastomer cure kinetic parameters estimation, Polymer Testing, 32 (2013) 9-14. https://doi.org/10.1016/j.polymertesting.2012.08.012

38. PJ. Carreau, Rheological equations from molecular network theories. Trans Soc Rheol 16 (1972) 99-127. https://doi.org/10.1122/1.549276

39. M. L. Williams, R. F. Landel, J. D. Ferry, The Temperature Dependence of Relaxation Mechanisms in Amorphous Polymers and Other Glass-Forming Liquids, Journal of the $\begin{array}{lllll}\text { American } & \text { Chemical } & \text { Society, } & 77 & \text { (1955) }\end{array}$ http://dx.doi.org/10.1021/ja01619a008

40. WE. Claxton, JW. Liska, Calculation of state of cure in rubber under variable timetemperature conditions. Rubber Age 95 (1964) 237. https://doi.org/10.5254/rct.16.83774

41. MR. Kamal, S. Sourour, Kinetics and thermal characterisation of thermoset cure. Polym Eng Sci 13 (1973) 59. https://doi.org/10.1002/pen.760130110

42. M.R. Erfanian, M. Anbaesooz, M. Moghiman, A three dimensional simulation of a rubber curing process considering variable order of reaction, Applied mathematical modelling, 40 (2016) 8592 - 8604.

43. W. Six, G. Bex, J. De Keyzer, F. Desplentere, A. Van Bael, A novel method for the prediction of adhesive strength for two - component injection moulding of thermoplastics with thermoset rubbers, Conference paper in AIP conference proceedings, 2055 (2019) 070020, https://doie.org/10.1063/1.5084864. 


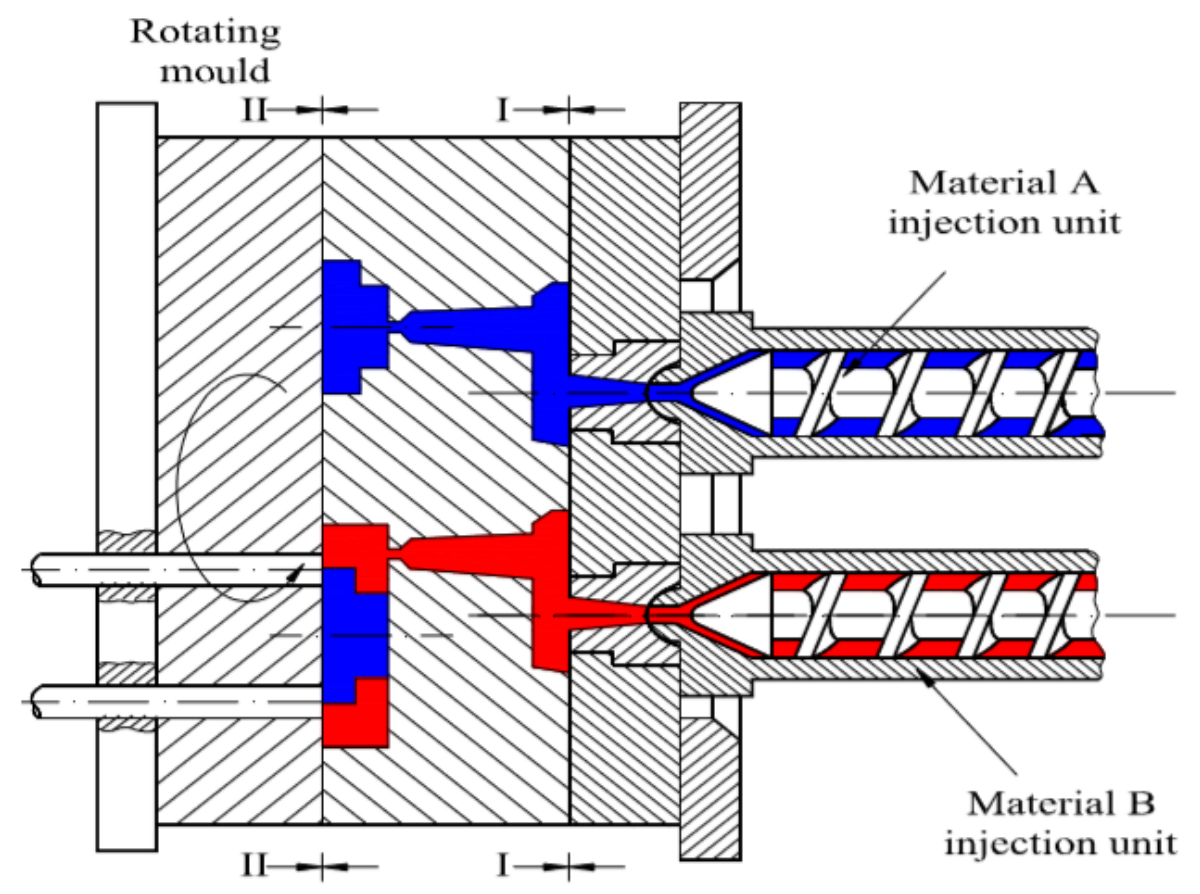

Figure 1. Schematic diagram of the two polymer moulds for the injection over-moulding process [23].
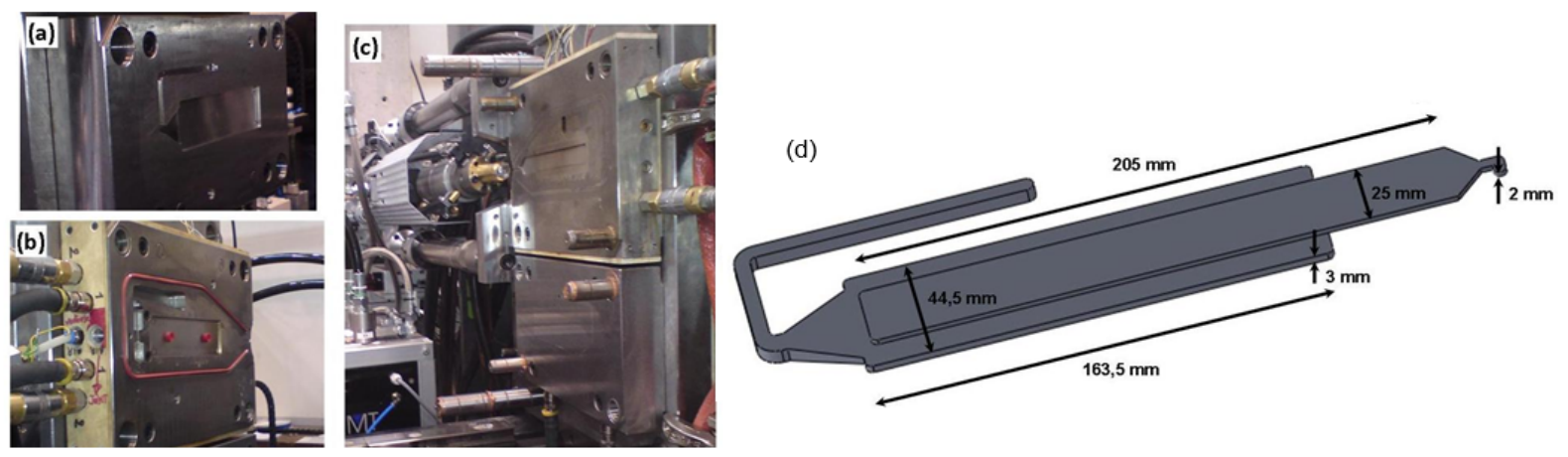

Figure 2. (a) Gate, runner, and mould cavity for the injection of polyamide, (b) View of the ejector and vacuum systems of the mould apparatus, (c) View of the second cavity for the LSR over-moulding, (d) Diagram of the standard peel test specimen geometry for the PA 66/LSR combination. 


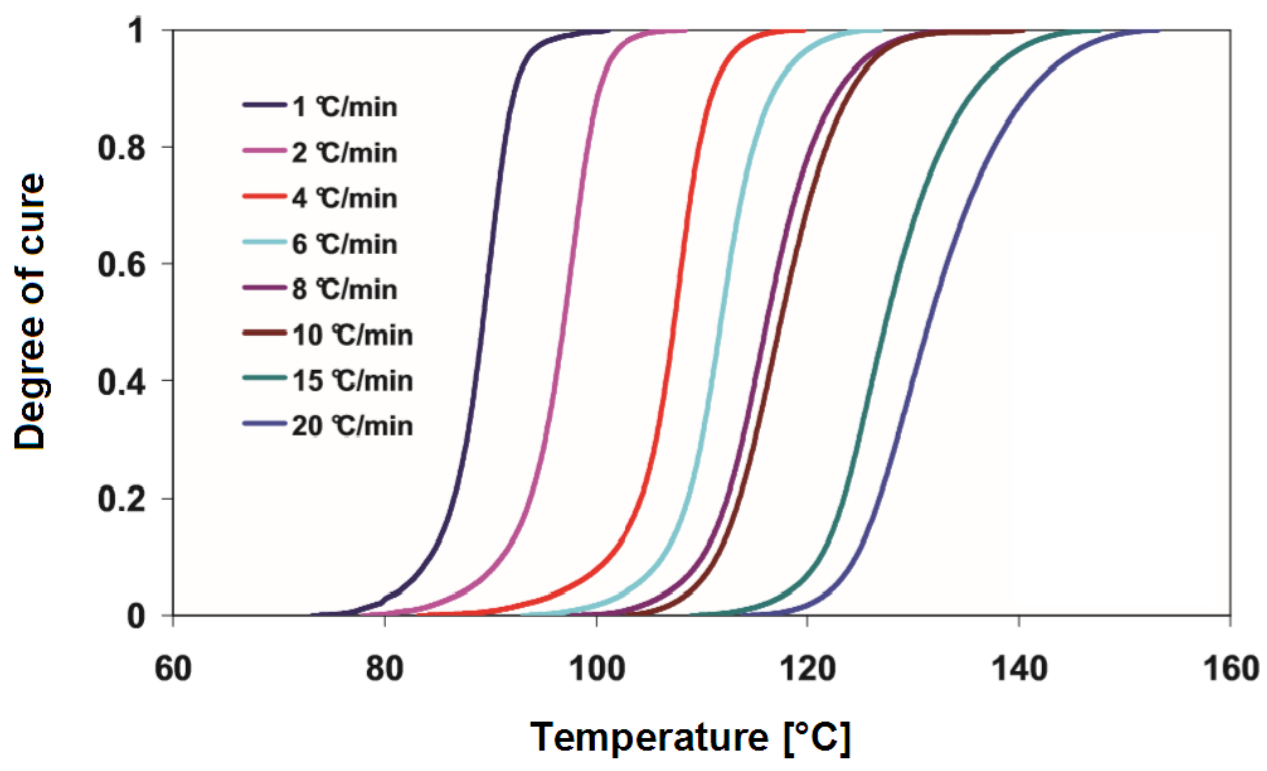

Figure 3. Degree of cureversus temperature measured by DSC at various thermal profiles.

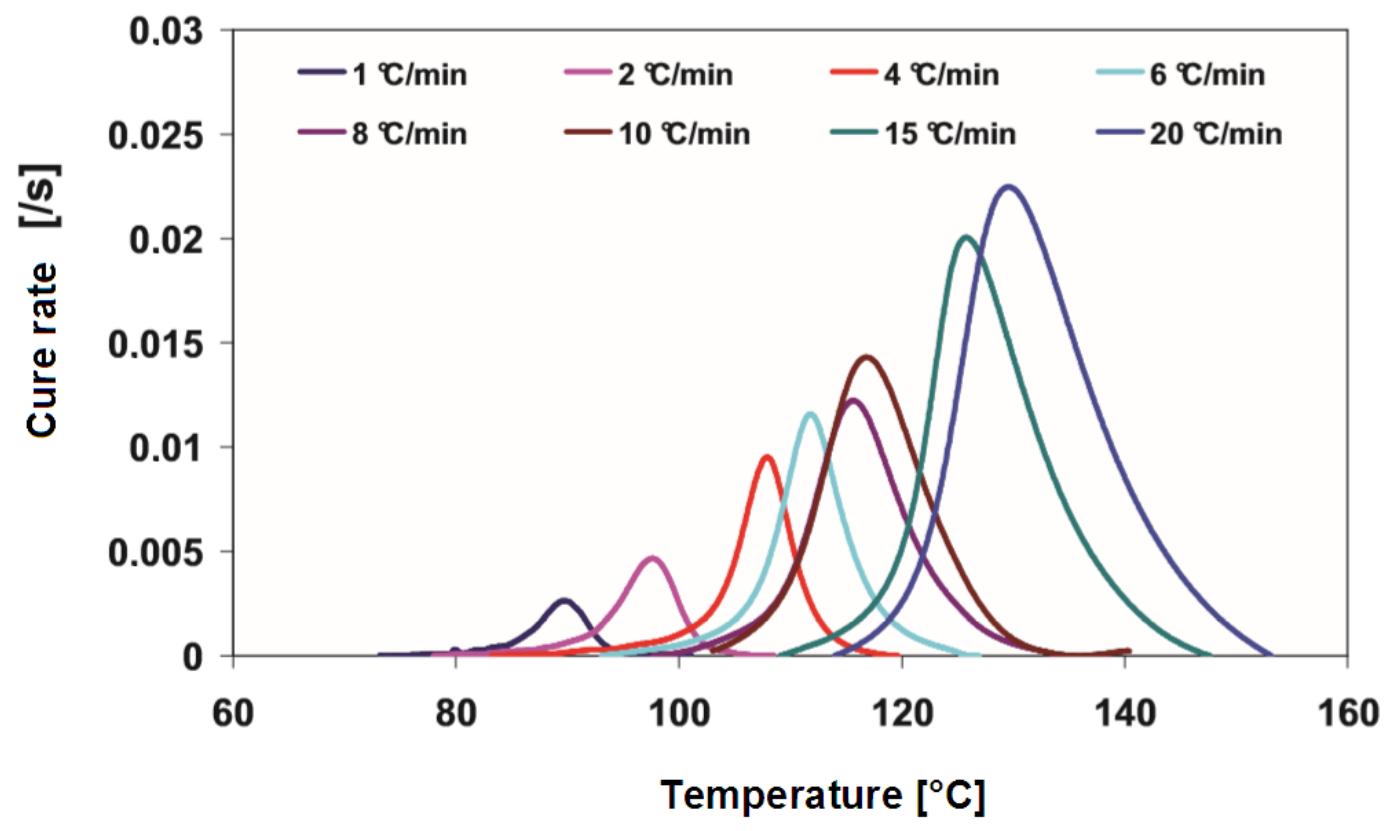

Figure 4. Cure rates versus temperature measured by DSC at various thermal profiles. 

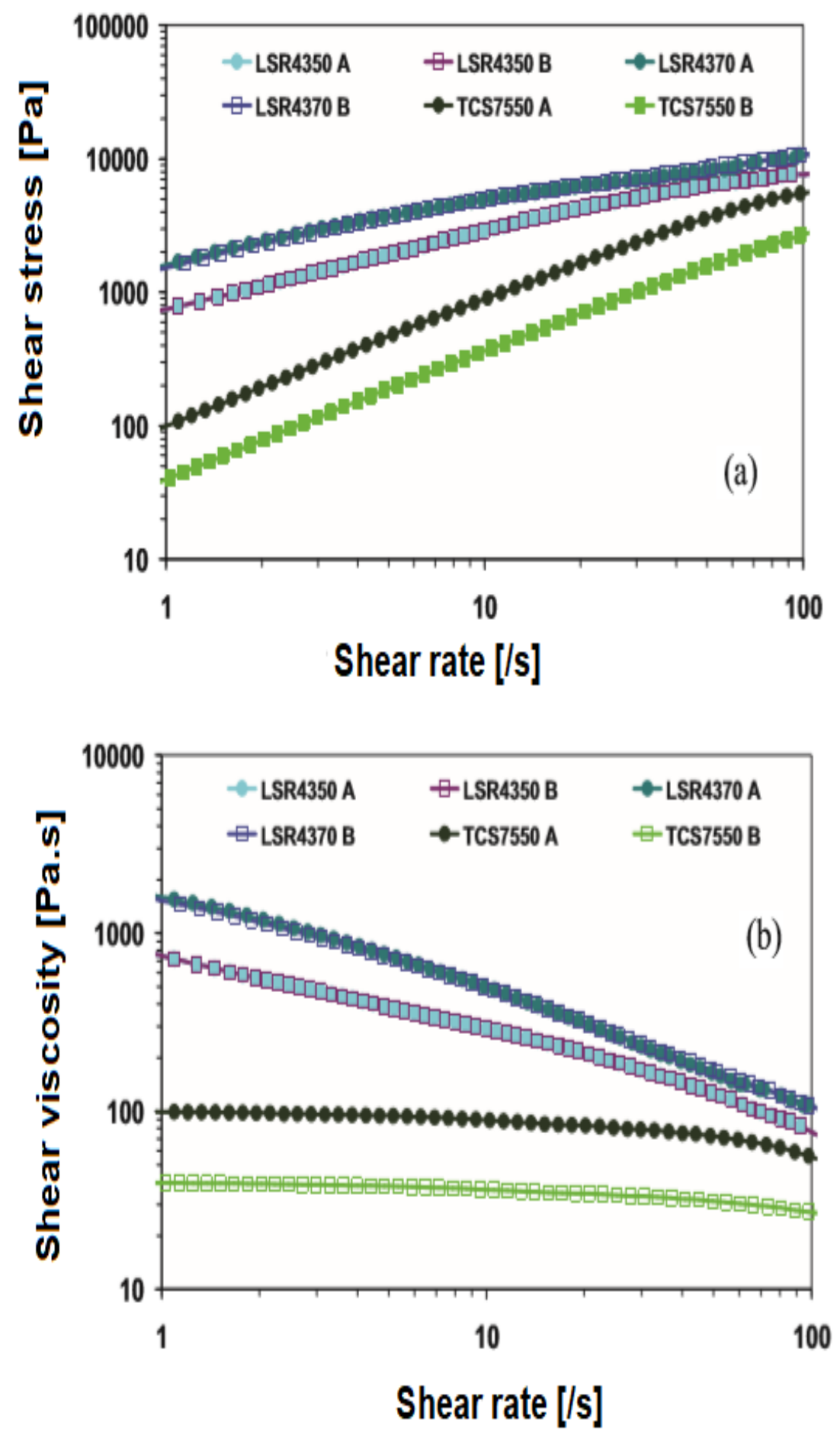

Figure 5. Rheogram tests of the two ingredients (A/B) of the LSR and TCS materials: a) shear stress versus shear rate and b) shear viscosity versus shear rate. 


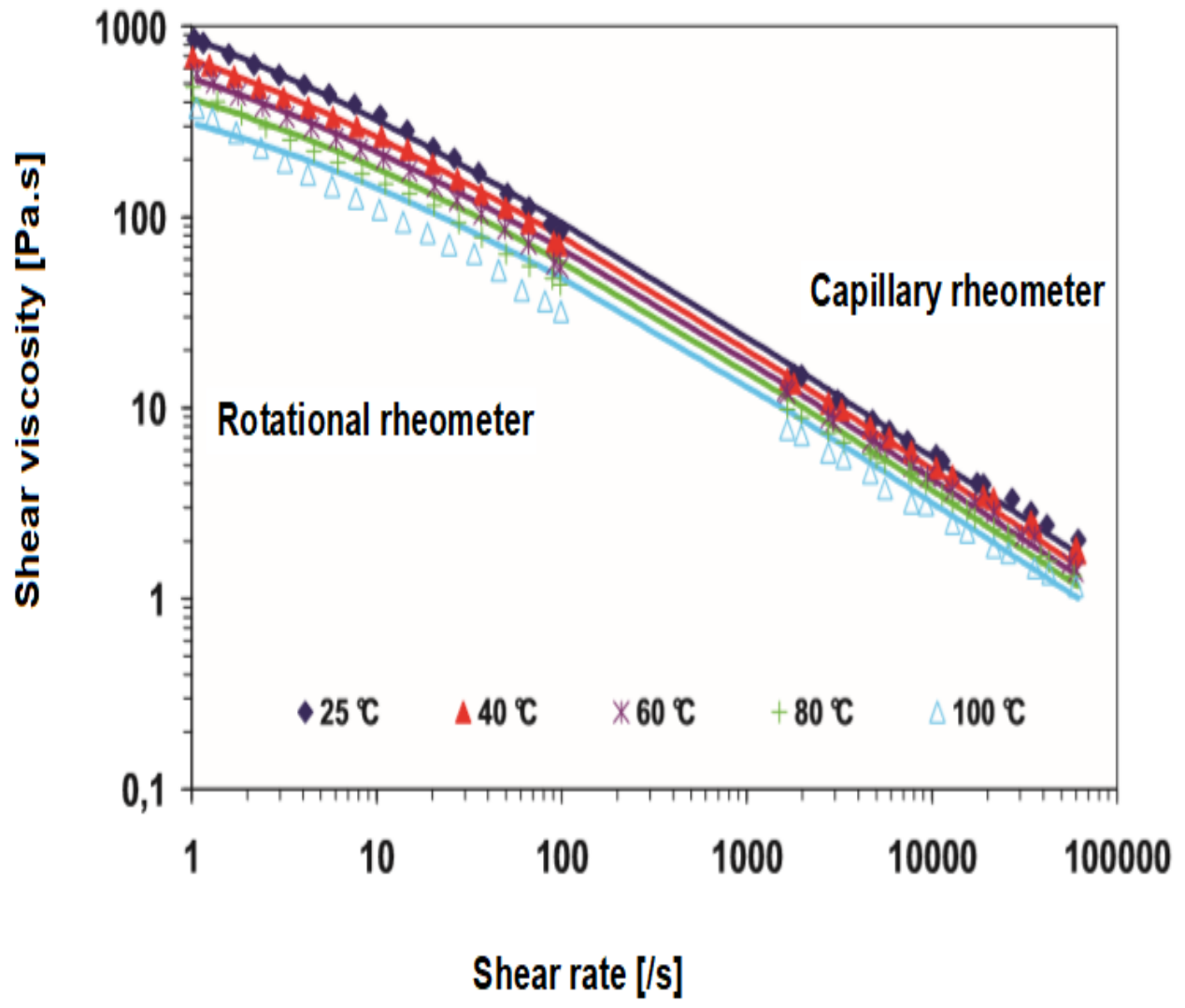

Figure 6. Experimental curves of shear viscosity versus shear rate include a wide range of shear rates (1 to $10^{5} \mathrm{~s}^{-1}$ ) and are performed at temperatures ranging from 25 to $100{ }^{\circ} \mathrm{C}$ for the elastomer material LSR4350A. 

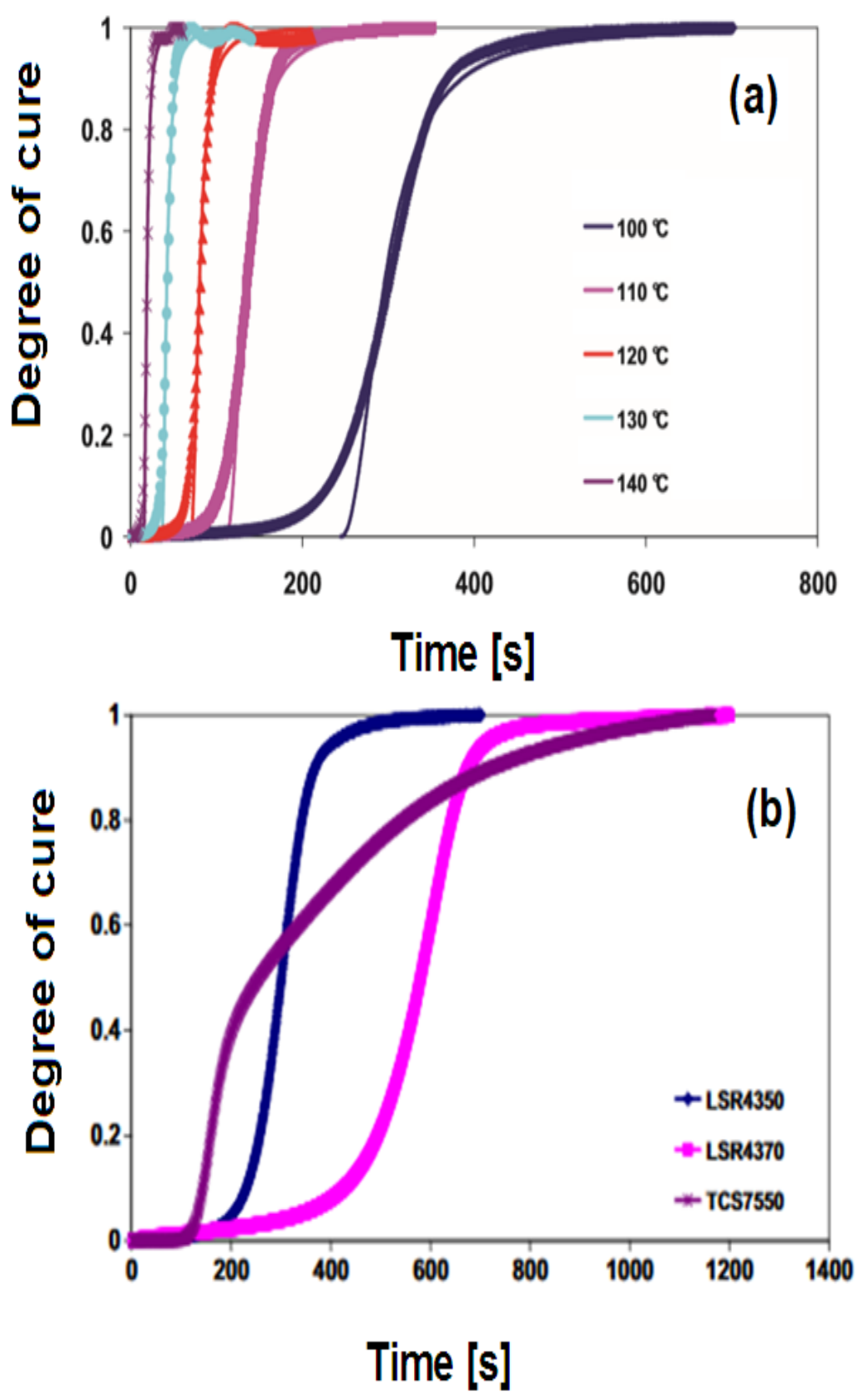

Figure 7. Experimental data of full cycles of curing versus time obtained at (a) various temperatures with LSR4350 and (b) $100{ }^{\circ} \mathrm{C}$ with the indicated liquid silicone rubber materials. 


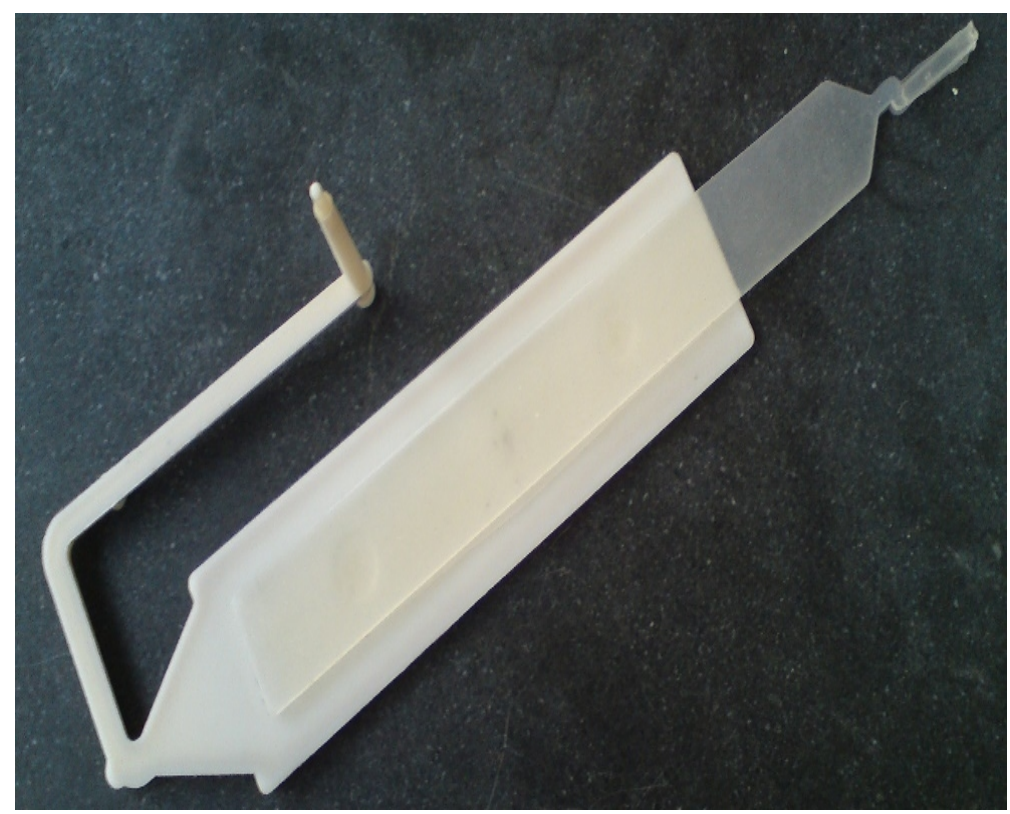

Figure 8. Over-mould of the PA66/LSR4350 peel test specimen.

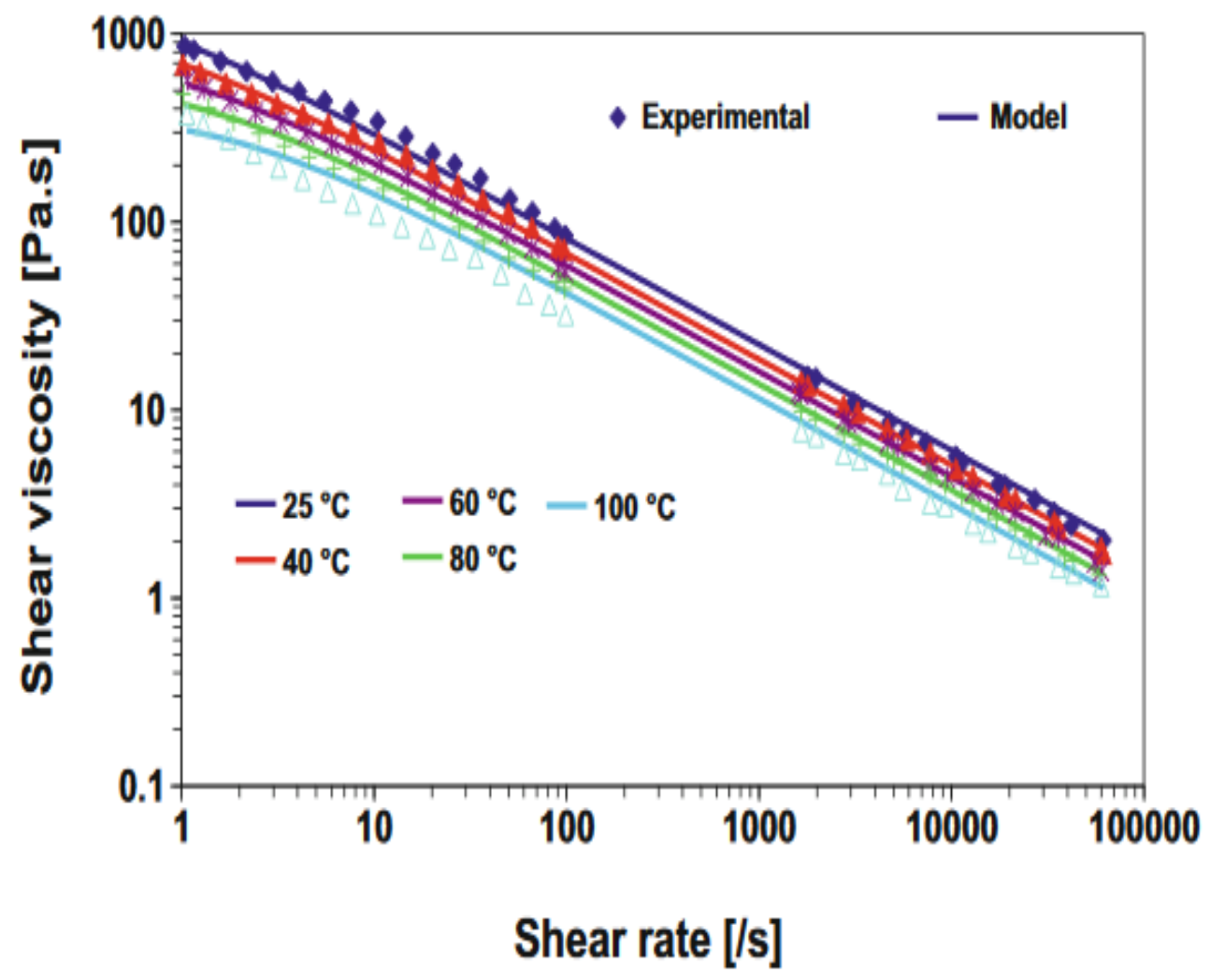

Figure 9. Shear viscosity versus shear rate at different temperatures and the fitting curves of Carreau-Yasuda and WLF models for the LSR4350 material. 


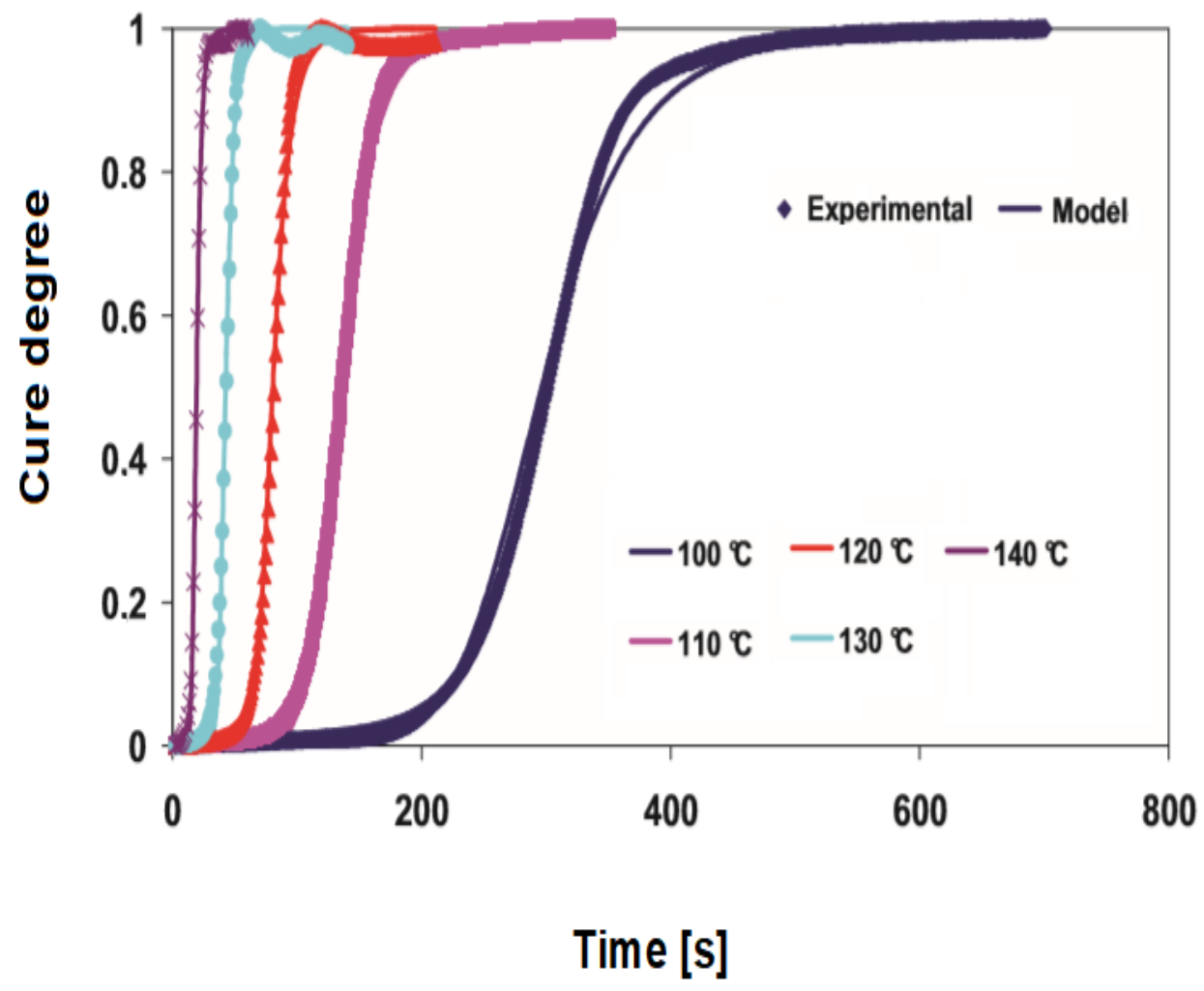

Figure 10. Comparison of the curing kinetics exhibited in experiments and those predicted by the Isayev-Deng model at the indicated temperatures for the LSR4350 material.

(a)

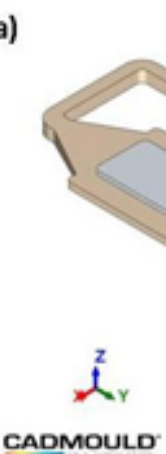

(b)

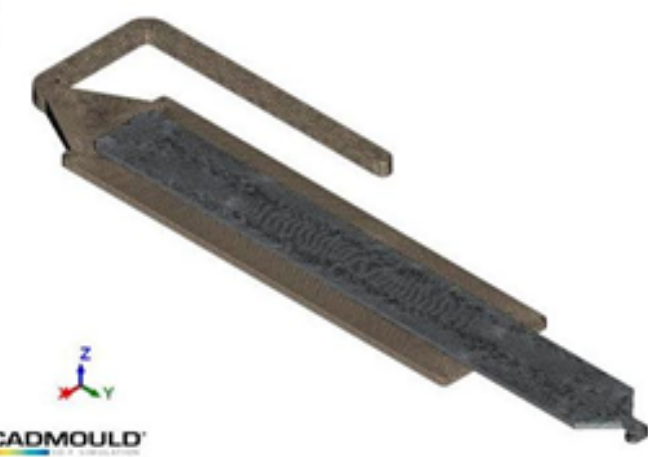

Figure 11. (a) Over-moulding injection peel test specimen for PA66/LSR materials. (b) A 3D mesh of the standard peel test with runners, gates, and sprues 


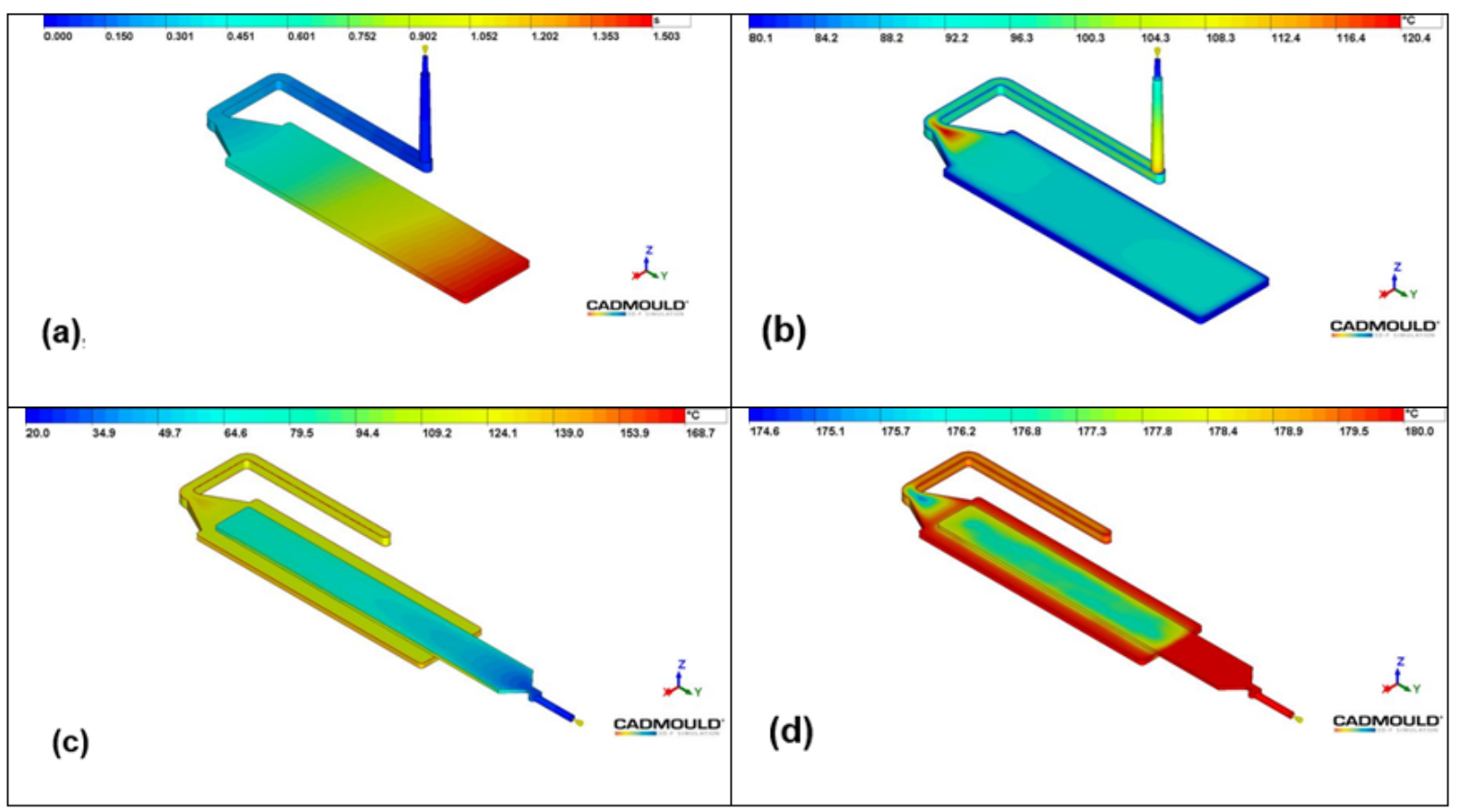

Figure 12. Numerical simulation showing the evolution of the flow front during filling and the temperature distribution at the end of filling for (a), (b) polyamide injection moulding, (c), (d) LSR over-moulding injection moulding.

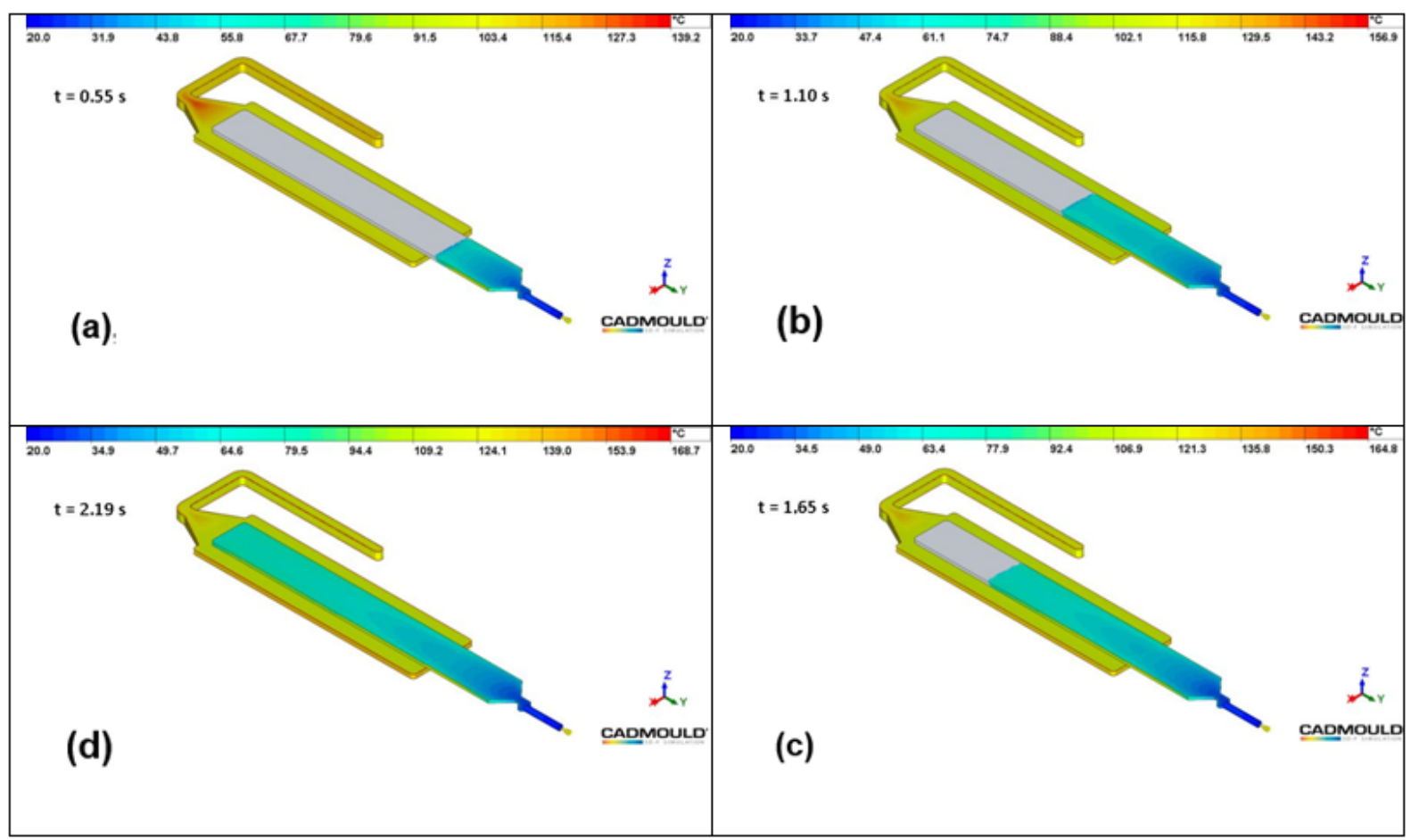

Figure 13. Evolution of the material front versus time obtained by the numerical simulation of over-moulding injection of LSR4350/PA66 for different filling times. 


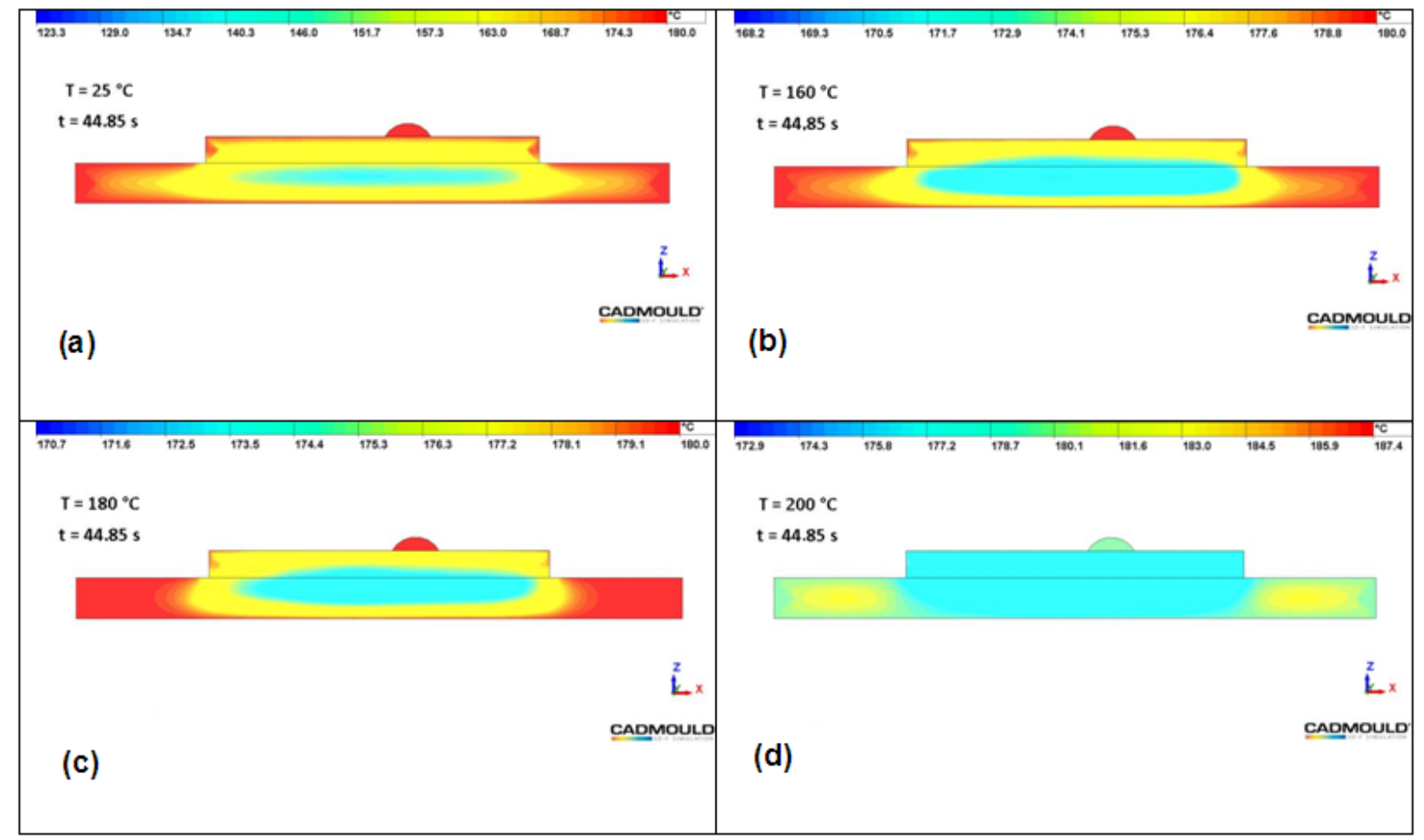

Figure 14. Numerical results of the temperature distribution during over-moulding injection obtained in the middle of the peel test specimen at different temperatures. 


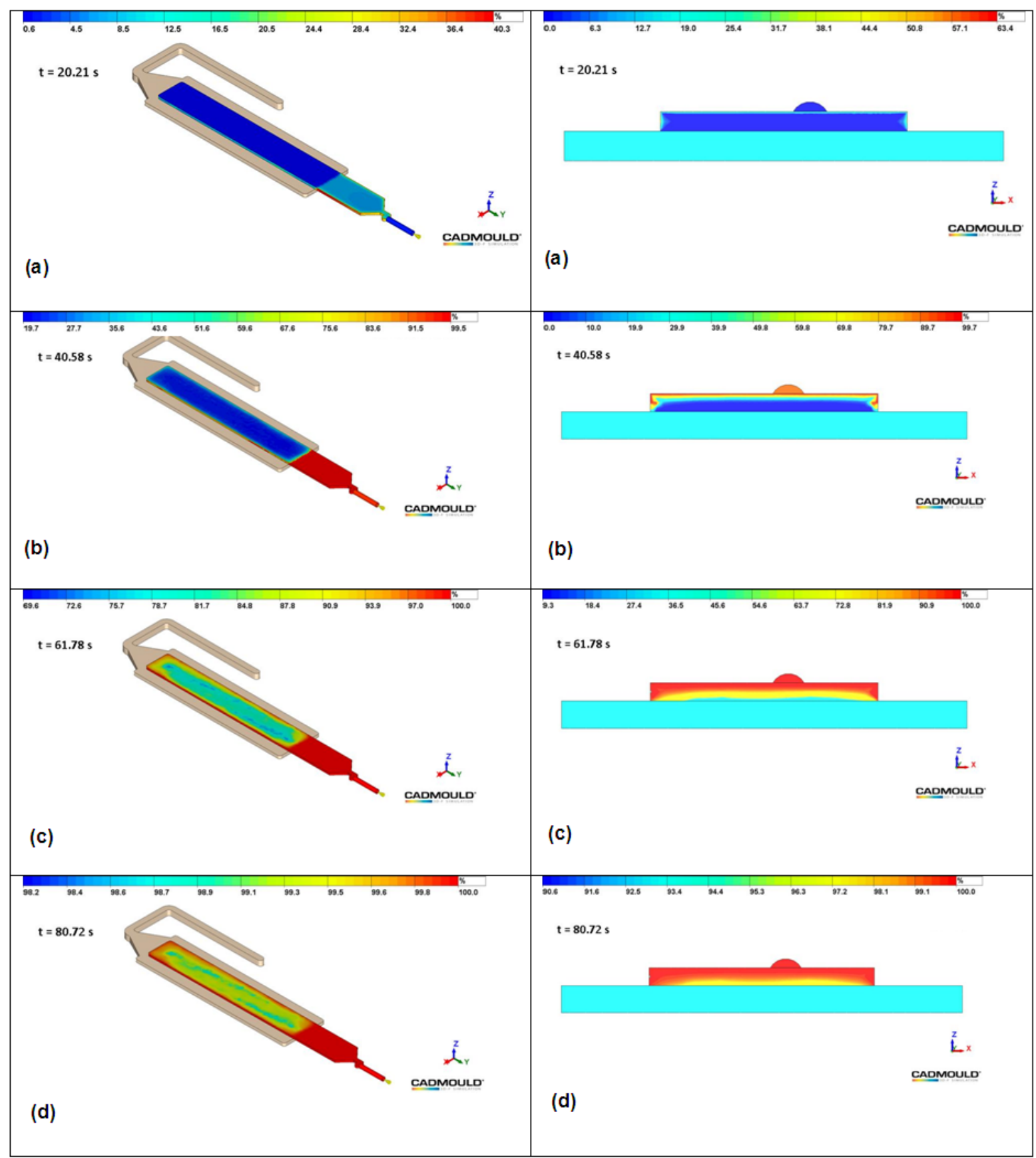

Figure 15. Numerical results of the degree of cure distributions at the end of the filling stage versus heating time for the LSR4350/PA66 at the middle of the standard peel test specimen. 

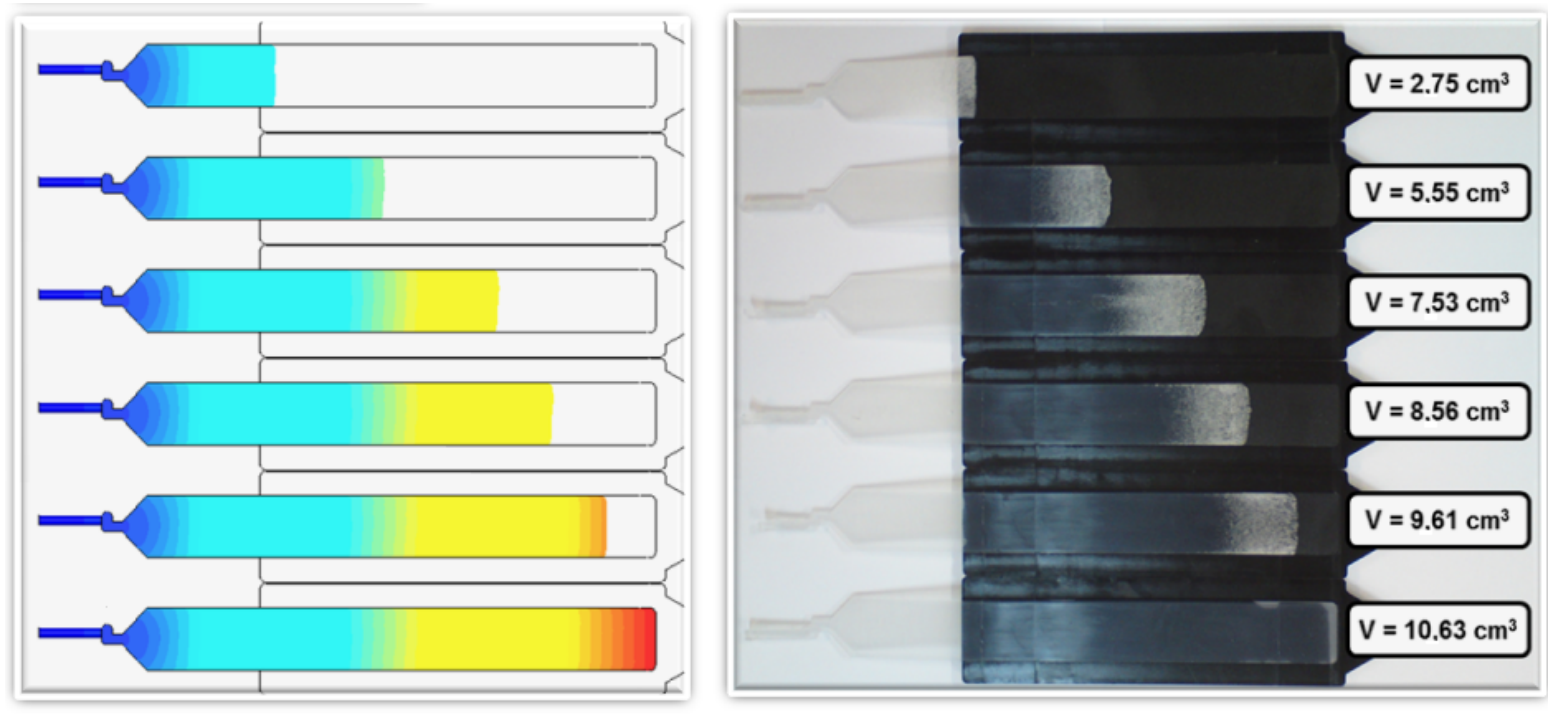

Figure 16. Comparison between the predicted and experiment flow-front measurements of the LSR material injected at different filling volumes in over-moulding injection tests. 


\section{Declaration of interests}

पThe authors declare that they have no known competing financialinterestsor personal relationships that could have appeared to influence the work reported in this paper.

$\square$ The authors declare the following financial interests/personal relationships which may be considered as potential competing interests:

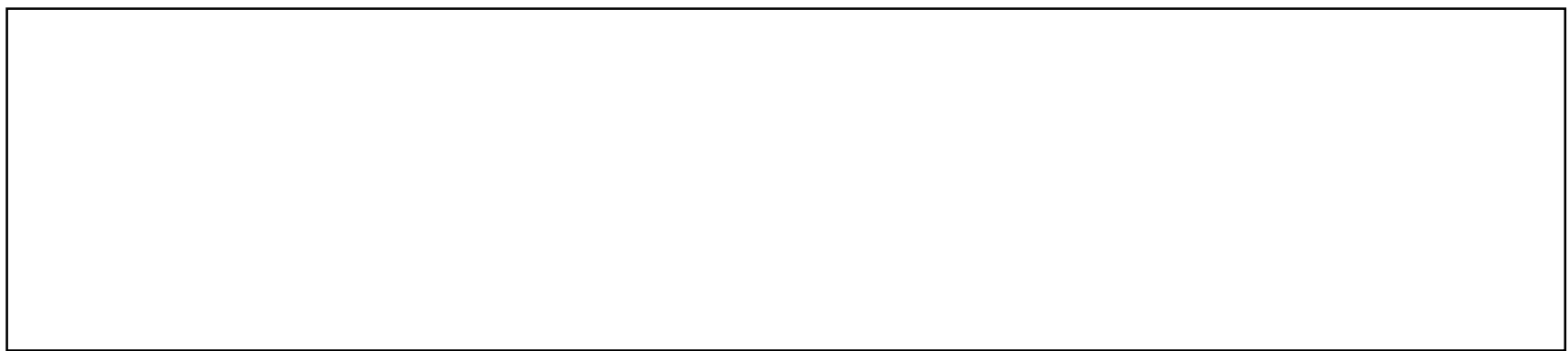


June 25,2020

To

Prof. Ulf W. Gedde, PhD

Editor, Polymer Testing

Dear Sir,

I am pleased to submit the revised version of our research article entitled 'Experimental and numerical investigations of bi-injection moulding of PA66/LSR peel test specimens' for publication in Polymer Testing. The reviewer's comments have been addressed, and our responses are provided below.

We believe that the revised manuscript is acceptable for publication.

This manuscript has not been published, nor is it under consideration for publication elsewhere. We have no conflicts of interest to disclose.

Thank you for your consideration.

Sincerely,

Dr. M. Sahli

Univ. Bourgogne Franche-Comté, FEMTO-ST Institute, CNRS/UFC/ENSMM/UTBM, Department of Applied Mechanics, 25000 Besançon, France

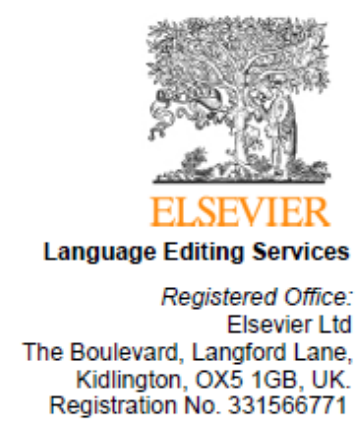

To whom it may concern

The paper "Experimental and numerical investigation of bi-injection moulding process of the peel test specimen PA66/LSR" by mohamed sahli was edited by Elsevier Language Editing Services.

Kind regards,

Elsevier Webshop Support 


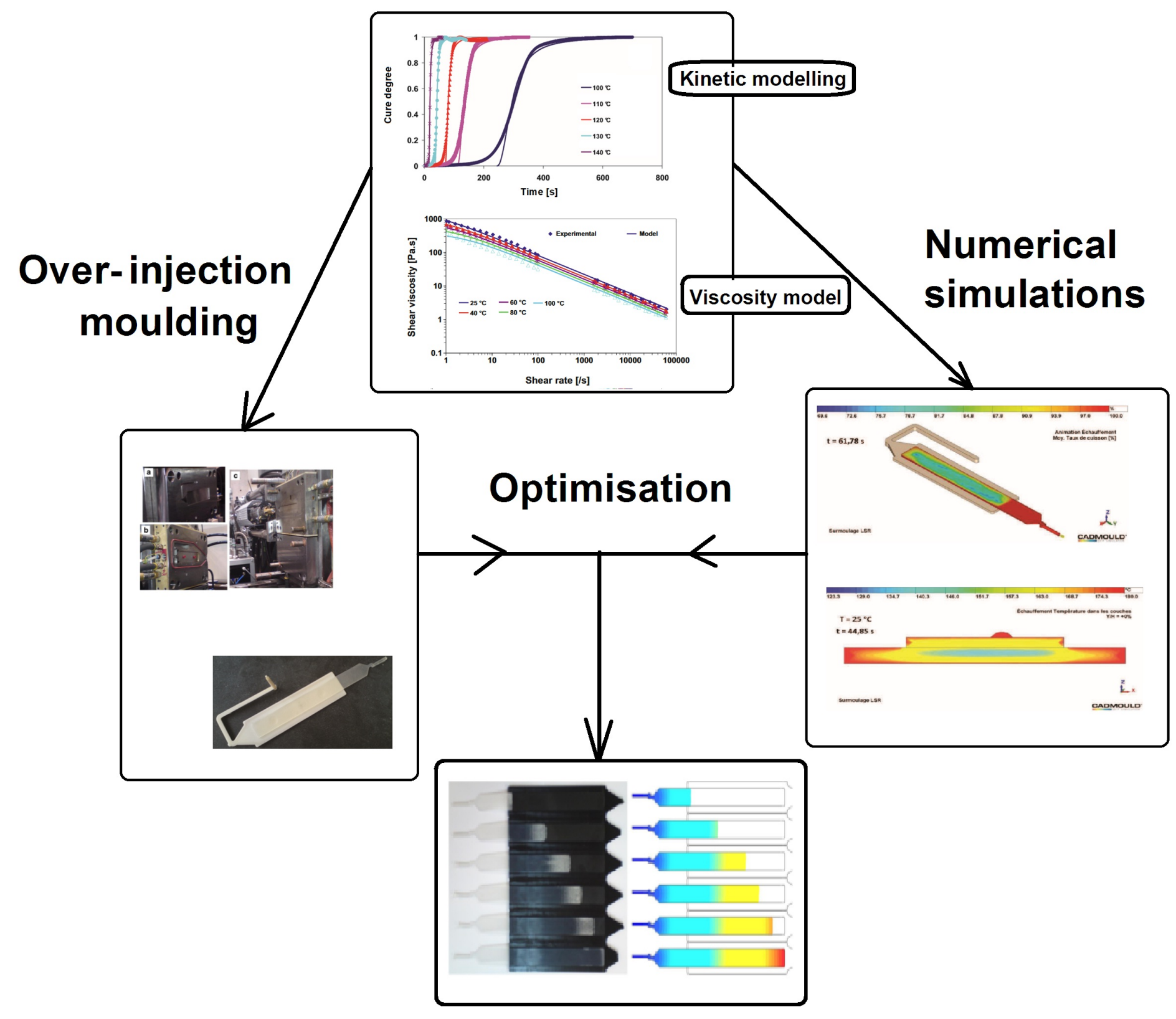

